\title{
Financing Constraints and a Firm's Decision and Ability to Innovate: \\ Establishing Direct and Reverse Effects
}

By

Vassilis Hajivassiliou

Frédérique Savignac

DISCUSSION PAPER NO 594

DISCUSSION PAPER SERIES

June 2007

Vassilis Argyrou Hajivassiliou is a Reader in the LSE Department of Economics and an FMG Research Associate. He was born in Nicosia and received a B.Sc. and a M.Sc. in Economics from the LSE in 1980 and 1981 respectively. After earning his Ph.D. from M.I.T. in 1985 under the supervision of Professor Daniel McFadden, he was appointed an Assistant Professor at Yale University and was promoted to Associate Professor in 1991, a position he held until 1996 when he moved to the LSE. He has held visiting professorships at the universities of Columbia and Toulouse. Frédérique Savignac is currently researcher at the Research Department of the Banque de France. She received her PhD from the Université Paris I Panthéon Sorbonne in November 2006. The thesis entitled "The financing of innovative firms" was supervised by Prof. Patrick Sevestre. Any opinions expressed here are those of the authors and not necessarily those of the FMG. The research findings reported in this paper are the result of the independent research of the authors and do not necessarily reflect the views of the LSE. 


\title{
Financing Constraints and a Firm's Decision and Ability to Innovate: Establishing Direct and Reverse Effects
}

\author{
by \\ Vassilis Hajivassiliou, Department of Economics, LSE \\ and \\ Frédérique Savignac, Banque de France
}

June 2007

\begin{abstract}
The paper analyzes the existence and impact of financing constraints as a possibly serious obstacle to innovation by firms. Direct measures of financing constraints are employed using survey data collected by the Banque de France and the European Commission, which overcomes the problems with the traditional approach of trying to deduce the existence and impact of financing constraints through the significance of firm wealth variables. The econometric framework employed for this study is the simultaneous bivariate probit with mutual endogeneity. The paper discusses the important identification issue of coherency conditions in such LDV models with endogeneity and flexible temporal and contemporaneous correlations in the unobservable error terms. Conditions for coherency as discussed in the existing literature are reviewed and shown to be rather esoteric. Two novel methods for establishing coherency conditions are presented, which have intuitive interpretations. Finally, the paper presents alternative approaches for achieving coherency in models hitherto classified as incoherent through the use of prior sign restrictions on model parameters. This allows us to obtain estimates of the interaction between financing constraints and a firm's decision and ability to innovate without forcing the econometric models to be recursive. Thus, direct as well as reverse interaction effects are obtained for the first time.

Keywords: Limited Dependent Variable Models, Coherency Conditions JEL Classifications: C51, C52, C15

\footnotetext{
*We have benefitted from constructive comments by participants at seminars at the London School of Economics and at the University of Toulouse, as well as at the 2006 Conference on Panel Data at the University of Cambridge and the 2006 Corporate Finance Conference in London. We thank in particular Alain Trognon, Paolo Volpin, Denis Gromb, and Antoine Faure-Grimaud. We also thank Ryan Giordano for expert research assistance. The usual disclaimer applies for any remaining errors.
} 
Address correspondence to:

E-mail: vassilis@lse.ac.uk

Address: Department of Economics

London School of Economics

London WC2A 2AE, England 


\section{Financing constraints and a Firm's Decision and Ability to Innovate: Establishing Direct and Reverse Effects}

\section{Introduction}

The paper analyzes the existence and impact of financing constraints as a possibly serious obstacle to innovation by firms. Direct measures of financing constraints are employed using survey data collected by the Banque de France, which overcomes the problems with the traditional approach in the past literature of trying to deduce the existence and impact of financing constraints through the significance of firm wealth variables. The main economic issues are discussed in Section 2. The econometric framework employed for this study is presented in Section 3. In the same section we discuss the important identification issue of coherency conditions in such LDV models with endogeneity and flexible temporal and contemporaneous correlations in the unobservable errors. The preliminary estimation results are presented in Section 4. In Section 5 we turn to conditions for coherency as derived in the existing literature and show them to be rather esoteric. Two novel methods for establishing coherency conditions are then presented, which have intuitive interpretations. In Section 6 the paper presents alternative approaches for achieving coherency in models traditionally classified as incoherent through the use of prior sign restrictions on model parameters. The new methodology is evaluated through a set of Monte-Carlo experiments described in Section 7. This allows us to obtain estimates, presented in Section 8, of the interaction between financing constraints and a firm's decision and ability to innovate without forcing the model to be recursive. Thus, direct as well as reverse interaction effects are obtained for the first time.

Section 9 explains how we exploit the nature of the available datasets to study whether, ceteris paribus, past financial distress or innovation failures can affect a firm's current experiences in these two dimensions. Section 10 describes our plan for future extensions of this research, while Section 11 concludes.

\section{Overview of Economic Issues}

This paper analyzes the existence and impact of financing constraints as a possibly debilitating obstacle to innovation by firms. According to the data employed, nearly one quarter of firms wishing to innovate report that their efforts towards innovation are hindered in a major way by financing constraints they encounter, leading them sometimes to delay the development and adoption of innovations, and sometimes even to abandon their innovative efforts. 
We identify the following leading causes of encountering financing constraints by innovative firms ${ }^{1}$ specifically because they attempt to be innovative:

First, two problems caused by asymmetric information between a firm and its prospective external financiers are highlighted, implying that the celebrated Modigliani and Miller theorem $(1958,1963)$ does not apply in such cases. The first such problem is that of "adverse selection", which justifies the earlier idea of Stiglitz and Weiss (1982) and may lead to quantity rationing in preference to allocation of funds through interest rates. More modern theories generate a hierarchy of sources of finance, namely (a) internal financing, (b) bank loans, and (c) equity financing through venture capital financiers, the three modes ranked in terms of increasing cost to innovative firms.

The second important informational asymmetry problem is "moral hazard" identified by Jensen and Meckling (1976), which is most serious for "start-up" firms, since for such newly established entities the usual dichotomy between owners' and managers' interests becomes even more pronounced.

The next leading cause identified in the paper is due to the fact that innovative firms typically have a higher fraction of intangible assets, implying they are not as able to raise the necessary collateral for low-cost financing. For example, special human expertise and other specific human capital may not be readily marketable outside a specific firm and hence bankers may be unwilling to grant loans based on such assets.

A key question we attempt to answer econometrically involves the incidence of financing constraints, and in particular whether innovative firms encounter more significant such constraints ceteris paribus when they attempt to innovate. It is explained how accumulated wealth and ploughed-back past profits can play an important role in alleviating constraints, since they make internal financing more readily available to the firm. A near consensus in the literature accepts a significantly positive correlation between firm wealth and innovation, and takes this as evidence that firm wealth relaxes financing constraints. Instead, this paper aims at establishing a role of financing constraints based by innovating firms specifically because they are innovating, other things equal. Towards this end, the existence of constraints is not deduced indirectly through the common argument above, but is directly measured by employing real data on the encountering of binding financing constraints as reported by firms in surveys by the European Union, carried out in 4 waves since 1990 (CIS1-CIS4), as well as in a French survey about the financing of innovation (FIT). Firms with 20+ employees were surveyed with a response rate of $85 \%$, while every firm with $500+$ employees is included in the datasets. The financing constraint variables we employ are described in detail in the Data Appendix. An important shortcoming of our data is that firms were asked to respond as to whether their plans to innovate were thwarted

\footnotetext{
${ }^{1}$ Applying the definition of the Oslo manual of the OECD and following Savignac (2006), we characterize as innovative a firm that introduces or develops a product or process innovation, or is in process of doing so.
} 
by the presence of financing constraints, and not whether their overall investment plans were thus seriously hindered. We are currently investigating the availability of such direct measures of overall financing constraints from other sources, notably the Banque de France and the French National Institute of Statistical and Economic Studies (INSEE). Such direct measures will allow us to answer whether innovative firms encounter more significant financing constraints pertaining to all their plans, not just for funding innovation. ${ }^{2}$

The key question we pose in this paper is whether binding financing constraints have a seriously adverse impact on innovation by firms. The approach here is innovative in several respects: firstly, unlike earlier literature direct measures of binding constraints are employed, instead of using traditional indirect proxy variables like firm wealth, accumulated profits, etc. Secondly, the econometric approach allows explicitly the existence of binding financing constraint to be endogenously determined. Our main finding is that there is a very significantly negative effect on innovation due to the presence of financing constraints, ceteris paribus. We also show that ignoring the endogeneity of the constraint indicator together with the endogenous decision of whether a firm wishes to innovate or not, induces very serious upward biases in the estimated coefficient. Consequently, a satisfactory resolution to an existing paradox is produced: not taking correct account of the endogeneity of financing constraints, leads one to incorrectly conclude that presence of financing constraints and innovation are positively correlated. We now give a simple illustration of the nature of this paradox:

Suppose one half of the firms do not wish to innovate, and hence do not face binding financing constraints by banks. The other half of firms who wish to innovate, approach the banks for a loan. For simplicity, let us say that half of them face a binding constraint and are denied their request for loan by the bank, while the other half are granted their request. Consequently, three quarters of firms end up not innovating ( $1 / 2$ who did not wish to and did not face finance constraints (group A), plus $1 / 4$ who wished to innovate but were refused the loan (group B)), while only 1/4 end up innovating (wished to and were granted their loan request (group C)). Group A of size 1/2 exhibits positive correlation between constraints and innovation (did not innovate, did not face constraints), while groups $\mathrm{B}$ of size $1 / 4$ and $\mathrm{C}$ of size $1 / 4$ exhibit negative correlation (B: did not innovate because of high financing constraints, $\mathrm{C}$ : innovated because of low constraints). If we select only the potentially innovating firms $(\mathrm{B}+\mathrm{C})$ the correlation is very negative. If we average also group $\mathrm{A}$, the overall correlation will be significantly higher, namely 0 in this example.

It should be self-evident that the traditional approaches of testing for presence of binding financing constraints indirectly by checking for the importance of firm

\footnotetext{
${ }^{2}$ Savignac (2006) finds that innovative firms appear to face significantly reduced probabilities of bank loans specifically because of their innovative activities. In addtion, she finds that the bank loans for the innovative firms that were successful in securing them are in fact at a significantly lower interest rate on the average.
} 
wealth, past profits, etc., can be seriously misleading. For example, it could be that richer firms may wish to invest more and hence need more funds simply because they anticipate future profits, not just because they are able to borrow more because they face lower constraints. A simple analogy with studying the intertemporal consumption decision is quite illuminating: the Euler equation framework with rational expectations implies that current consumption decisions should be unaffected by current income. The traditional financial constraints empirical analyses are akin to concluding that economic agents face binding liquidity constraints by observing econometrically that current consumption decisions are significantly affected by the level of current income, which of course does not necessarily follow.

To overcome such shortcomings, our econometric analysis here follows Savignac (2006) and proceeds to employ three direct measures of financing constraints, obtained from the FIT ("Financement de l'Innovation Technologique") database collected by SESSI: (i) unavailability of new financing; (ii) searching and waiting for new financing; and (iii) too high a cost of new financing. The sample consists of 3710 firms corresponding to an overall response rate of about $70 \%$ (and $60 \%$ for large firms). See the Data Appendix for an extensive discussion of our data sources, and of the variables we employ as best proxies for the theoretical economic quantities and their characteristics. $^{3}$

The dataset is rich enough to allow us to focus econometrically on the impact of financial constraints as such on limiting innovation, while considering directly important economic factors which may limit innovation, such as: market risk, unavailability of suitable personnel, too high costs, excessive costs for abandoning innovation, and not sufficient knowledge of available financing. ${ }^{4}$

These databases are merged with the "Centrale de Bilans" (CdB) of the Banque de France, which contains full balance sheet data on the firms in the sample thus giving us direct data on bank loans, tangible and intangible assets, as well as sources of finance. ${ }^{5}$

A bivariate probit model is estimated with these data, with one equation characterizing whether or not a firm chooses to be innovative, and the other the (endogenous) probability that a firm will face a binding financing constraint, i.e.,

$$
\begin{aligned}
\operatorname{Prob}(\text { Innovate? })= & f(\mathrm{FC}, \text { size, market power, } \\
& \text { "push" technological opportunities, } \\
& \text { latent consumer demand for new products, ...) }
\end{aligned}
$$

\footnotetext{
${ }^{3}$ For further details, we refer the reader to Savignac (2006), Annexes A-C.

${ }^{4}$ Using the standard terminology of the existing literature, this is the distinction between financial and economic distress factors.

${ }^{5}$ The response rate for $\mathrm{CdB}$ is just above $50 \%$.
} 
Prob(Binding Financing Constraint? $=f($ Innovation, size,

$$
\text { guarantees/collateral/corporate bonds, ...) }
$$

We explain carefully the need to work only with recursive versions of the bivariate probits to guarantee "coherency". Our preferred version is to drop Innovation from the second equation and keep "Financing Constraints" in the first, though in the "Robustness Checks" of Savignac (2006), she also presents results from dropping "Financing Constraints" from the first equation while keeping Innovation in the second. Four versions of the estimated models are explored in Section 4: version (i) includes measures of financing constraints but not the "Financing Constraints" incidence indicator itself; version (ii) include measures of financing constraints but not the "Financing Constraints" incidence indicator itself but adds the BdF risk rating measure, which is found very significant; version (iii) employs the reported indicator dummy of "Financing Constraints" included treating it as exogenous; while version (iv) allows the reported indicator dummy of "Financing Constraints" to be included as endogenous.

In Sections (6) and (7) we derive the necessary econometric methodology to allow us to investigate a simultaneous role for the two cross effects using a priori sign restrictions on the model coefficients.

A key finding confirms the importance of allowing for endogeneity of "Financing Constraints": the impact of the "Financing Constraints" indicator has an extremely significant statistically negative effect on innovation, with the size of the effect almost tripled once endogeneity is introduced.

Another key finding is that repeating the estimations on the full sample as opposed to just the potentially innovating firms reinforces the impact of endogeneity and the role of sample selection described earlier: treating "Financing Constraints" as exogenous gives a positive (though insignificant) coefficient, while estimating with endogeneity confirm the very significantly negative effect found in the subsample estimations.

We are in the process of investigating other versions of the simultaneous bivariate probit models presented above:

- Additional "liquidity" measures should be included in order to distinguish better between financial and economic distress. In particular, available cash stock is likely to be an important conditioning factor.

- Surprisingly, belonging to a holding group does not seem to help innovation nor lead to less financial distress. Perhaps this is because we did not allow for the possibility that the critical factor may be the size of the holding group.

- The likely endogeneity of the profitability and asset tangibility measures needs to be addressed. 


\section{The Econometric Problem of "Coherency" in LDV Models}

We now turn to the fundamental identification issue of coherency conditions in LDV models with endogeneity and flexible temporal and contemporaneous correlations in the unobservable errors. The methods we develop here allow us to achieve coherency in models traditionally classified as incoherent through the use of prior restrictions on model parameters.

\subsection{Simultaneous LDV Model with Two Binary Responses}

$$
\begin{aligned}
& y_{1 i t}=\tau_{1}\left(y_{1 i t}^{*} \equiv\left[h_{1}\left(x_{1 i t}^{\prime} \beta_{1}, y_{2 i t} \gamma\right)+\epsilon_{1 i t}\right]\right) \\
& y_{2 i t}=\tau_{2}\left(y_{2 i t}^{*} \equiv\left[h_{2}\left(x_{2 i t}^{\prime} \beta_{2}, y_{1 i t} \delta\right)+\epsilon_{2 i t}\right]\right)
\end{aligned}
$$

Typical coherency condition: $\gamma \cdot \delta=0$

Gourieroux, Laffont, and Monfort (1981) explain condition in terms of there being a valid function from $\left(\epsilon_{1 i t}, \epsilon_{2 i t}\right)$ to the observable endogenous variables $\left(y_{1 i t}, y_{2 i t}\right)$.

Lewbel (2005) establishes necessary and sufficient for coherency by approaching problem as requiring a valid reduced form system for $\left(y_{1 i t}, y_{2 i t}\right)$.

To give an illustration of the reduced form approach, we proceed as follows:

If $\delta=0$ then the reduced form equation for $y_{2 i t}$ is:

$$
y_{2 i t}=\tau_{2}\left(h_{2}\left(x_{2 i t}^{\prime} \beta_{2}\right)+\epsilon_{2 i t}\right)
$$

and hence the reduced form equation for $y_{1 i t}$ is given by:

$$
y_{1 i t}=\tau_{1}\left(h_{1}\left(x_{1 i t}^{\prime} \beta_{2}, \gamma \cdot \tau_{2}\left(h_{2}\left(x_{2 i t}^{\prime} \beta_{2}\right)+\epsilon_{2 i t}\right)\right)+\epsilon_{1 i t}\right)
$$

\subsection{Leading Case: Joint Binary Model}

Leading case: the binary response threshold crossing model defined by:

$$
\tau_{j}(z) \equiv \mathbf{1}(z>0)
$$

In this case, $\left(y_{1}, y_{2}\right) \in\{(1,1),(1,0),(0,1),(0,0)\}$ such that:

\begin{tabular}{|l|l|l|l|}
\hline$\left(y_{1}, y_{2}\right)$ & $y_{1}^{*}$ &, & $y_{2}^{*}$ \\
\hline$(1,1)$ & $x_{1}^{\prime} \beta_{1}+\gamma+\epsilon_{1}>0$ &, & $x_{2}^{\prime} \beta_{2}+\delta+\epsilon_{2}>0$ \\
\hline$(1,0)$ & $x_{1}^{\prime} \beta_{1}+\epsilon_{1}>0$ &, & $x_{2}^{\prime} \beta_{2}+\delta+\epsilon_{2}<0$ \\
\hline$(0,1)$ & $x_{1}^{\prime} \beta_{1}+\gamma+\epsilon_{1}<0$ &, & $x_{2}^{\prime} \beta_{2}+\epsilon_{2}>0$ \\
\hline$(0,0)$ & $x_{1}^{\prime} \beta_{1}+\epsilon_{1}<0$ &, & $x_{2}^{\prime} \beta_{2}+\epsilon_{2}<0$ \\
\hline
\end{tabular}




\subsection{General Explanation and Illustrative Applications}

In general, in the absence of coherency conditions, there will be overlaps and/or gaps in the domain of $\left(\epsilon_{1}+x_{1}^{\prime} \beta_{1}, \epsilon_{2}+x_{2}^{\prime} \beta_{2}\right)$.

We now develop a joint binary probit model to study the impact of financing constraints on a firm's decision and ability to innovate.

Define two latent dependent variables $I_{i t}^{*}$ and $F_{i t}^{*}$ and two binary limited dependent variables $I_{i t}$ and $F_{i t}$ as follows:

$$
\begin{gathered}
I_{i t}=\left\{\begin{array}{lll}
1 & \text { if } & I_{i t}^{*} \equiv x_{i t}^{I} \beta^{I}+\gamma F_{i t}+\epsilon_{i t}^{I}>0 \\
0 & \text { if } \quad I_{i t}^{*} \equiv x_{i t}^{I} \beta^{I}+\gamma F_{i t}+\epsilon_{i t}^{I} \leq 0
\end{array}\right. \\
F_{i t}=\left\{\begin{array}{lll}
1 & \text { if } & F_{i t}^{*} \equiv x_{i t}^{F} \beta^{F}+\delta I_{i t}+\epsilon_{i t}^{F}>0 \\
0 & \text { if } & F_{i t}^{*} \equiv x_{i t}^{F} \beta^{F}+\delta I_{i t}+\epsilon_{i t}^{F} \leq 0
\end{array}\right.
\end{gathered}
$$

For a typical it observation, the probability $\operatorname{Prob}\left(I_{i t}, F_{i t} \mid X, \theta\right)$ is characterized by the constraints on the unobservables:

$$
\left(a^{I}, a^{F}\right)^{\prime}<\left(\epsilon^{I}, \epsilon^{F}\right)^{\prime}<\left(b^{I}, b^{F}\right)^{\prime}
$$

through the configuration:

\begin{tabular}{|l|l|l|l|c|c|}
\hline$I_{i t}$ & $F_{i t}$ & $a^{I}$ & $b^{I}$ & $a^{F}$ & $b^{F}$ \\
\hline 1 & 1 & $-x_{i t}^{I} \beta^{I}-\gamma$ & $\infty$ & $-x_{i t}^{F} \beta^{F}-\delta$ & $\infty$ \\
\hline 1 & 0 & $-x_{i t}^{I} \beta^{I}$ & $\infty$ & $-\infty$ & $-x_{i t}^{F} \beta^{F}-\delta$ \\
\hline 0 & 1 & $-\infty$ & $-x_{i t}^{I} \beta^{I}-\gamma$ & $-x_{i t}^{F} \beta^{F}$ & $\infty$ \\
\hline 0 & 0 & $-\infty$ & $-x_{i t}^{I} \beta^{I}$ & $-\infty$ & $-x_{i t}^{F} \beta^{F}$ \\
\hline
\end{tabular}




\section{The Importance of Simultaneity and Sample Se- lection}

We take as our starting point the results obtained by Savignac (2006) who studied the impact of financial constraints on the decision to innovate by assuming recursivity. The propensity to innovate is explained by the traditional determinants of innovation (firm size and market power, technology push, latent consumer demand) and by a qualitative indicator reflecting the financial difficulties encountered by firms to conduct their innovative projects. Simultaneously, the probability that a firm faces a binding financing constraint is explained by firm ex ante economic performances and financing structure. The results of these regressions are reported in tables 1 and 2 below. Without taking into account the endogeneity of the financial constraint, a surprising significant positive effect of this variable on the propensity to innovate is obtained (third column of tables $1 \mathrm{a}$ and $1 \mathrm{~b}){ }^{6}$

In sharp contrast, when endogeneity is accounted for, the estimated coefficient of the financial constraints becomes negative, as expected, while all other estimates remain largely unchanged (second column of tables $2 \mathrm{a}$ and $2 \mathrm{~b}$ ). Furthermore, a strong correlation between the errors of both equations is found when both equations are simultaneously estimated.

\footnotetext{
${ }^{6}$ Versions (a) of each table present results based from the full sample of 1940 firms, while in versions (b) we restrict the estimations to the subsample of 1082 potentially innovative firms only.
} 
Table 1.a

Propensity to Innovate Probit Ignoring Endogeneity

(full sample, nobs=1940)

\begin{tabular}{lcccccccc}
\hline & \multicolumn{2}{c}{ Model 1} & & \multicolumn{2}{c}{ Model 2} & & \multicolumn{2}{c}{ Model 3} \\
\cline { 2 - 3 } \cline { 8 - 9 } Variable & Coeff. & Std. & & Coeff. & Std. & & Coeff. & Std. \\
\hline Constant & $-2.51^{* * *}$ & 0.21 & & $-2.73^{* * *}$ & 0.26 & & $-2.61^{* * *}$ & 0.21 \\
Size & $0.32^{* * *}$ & 0.03 & & $0.23^{* * *}$ & 0.06 & & $0.33^{* * *}$ & 0.03 \\
Market share & -0.01 & 0.06 & & -0.03 & 0.06 & & -0.01 & 0.06 \\
TP4 & $1.76^{* * *}$ & 0.15 & & $1.74^{* * *}$ & 0.15 & & $1.66^{* * *}$ & 0.16 \\
TP3 & $1.25^{* * *}$ & 0.12 & & $1.22^{* * *}$ & 0.12 & & $1.19^{* * *}$ & 0.12 \\
TP2 & $0.82^{* * *}$ & 0.12 & & $0.80^{* * *}$ & 0.12 & & $0.77^{* * *}$ & 0.12 \\
Financial constraints & - & - & & - & - & & $0.55^{* * *}$ & 0.09 \\
Collateral amount & - & - & & $0.08^{*}$ & 0.041 & & - & - \\
Banking debt & - & - & & -0.001 & 0.001 & & - & - \\
Own financing & - & - & & 0.001 & 0.001 & & - & - \\
Profit margin & - & - & & $0.004^{* *}$ & 0.002 & & - & - \\
Industry dummies & misc & & & misc & & & misc & \\
Log lik & -1080.5 & & -1073.2 & & & -1060.3 & \\
\hline
\end{tabular}

Table 1.b

Propensity to Innovate Probit Ignoring Endogeneity (Potentially innovative firms, nobs $=1082$ )

\begin{tabular}{|c|c|c|c|c|c|c|}
\hline \multirow[b]{2}{*}{ Variable } & \multicolumn{2}{|c|}{ Model 1} & \multicolumn{2}{|c|}{ Model 2} & \multicolumn{2}{|c|}{ Model 3} \\
\hline & Coeff. & Std. & Coeff. & Std. & Coeff. & Std. \\
\hline Constant & $-1.22^{* * *}$ & 0.34 & $-1.11^{* *}$ & 0.51 & $-1.07 * * *$ & 0.35 \\
\hline Size & $0.27^{* * *}$ & 0.06 & $0.27^{* * *}$ & 0.06 & $0.27^{* * *}$ & 0.06 \\
\hline Market share & $0.76^{* * *}$ & 0.30 & $0.60^{* *}$ & 0.29 & $0.72^{* *}$ & 0.30 \\
\hline TP4 & $1.20^{* * *}$ & 0.24 & $1.18^{* * *}$ & 0.24 & $1.33^{* * *}$ & 0.24 \\
\hline TP3 & $0.81^{* * *}$ & 0.20 & $0.76^{* * *}$ & 0.20 & $0.88^{* * *}$ & 0.20 \\
\hline TP2 & $0.39^{* * *}$ & 0.19 & $0.33^{*}$ & 0.19 & $0.44^{* *}$ & 0.19 \\
\hline Financial constraints & - & - & - & - & $-0.52^{* * *}$ & 0.10 \\
\hline Collateral amount & - & - & -0.002 & 0.002 & - & - \\
\hline Banking debt & - & - & -0.007 & 0.004 & - & - \\
\hline Own financing & - & - & 0.002 & 0.004 & - & - \\
\hline Profit margin & - & - & $0.007^{* * *}$ & 0.002 & - & - \\
\hline Industry dummies & misc & misc & misc & misc & misc & misc \\
\hline Log lik & -516.2 & & -504.8 & & -501.9 & \\
\hline
\end{tabular}


Table 2.a

Innovation and Financing Constraints Joint Probit

Without Reverse Interaction Effects (full sample, nobs=1940)

\begin{tabular}{|c|c|c|c|c|}
\hline \multirow{3}{*}{ Innovation equation } & \multicolumn{2}{|c|}{ Single Equations } & \multicolumn{2}{|c|}{ Bivariate Probits } \\
\hline & \multirow[t]{2}{*}{ Coeff. } & \multirow[t]{2}{*}{ Std. } & \multirow[t]{2}{*}{ Coeff. } & \multirow[t]{2}{*}{ Std. } \\
\hline & & & & \\
\hline Constant & $-2.731^{* * *}$ & 0.225 & $-2.408^{* * *}$ & 0.290 \\
\hline Size & $0.304^{* * *}$ & 0.034 & $0.293^{* * *}$ & 0.034 \\
\hline Market share & 0.025 & 0.063 & 0.022 & 0.058 \\
\hline $\mathrm{TP} 4$ & $1.646^{* * *}$ & 0.165 & $1.572^{* * *}$ & 0.180 \\
\hline TP3 & $1.086^{* * *}$ & 0.132 & $1.030^{* * *}$ & 0.142 \\
\hline TP2 & $0.684^{* * *}$ & 0.128 & $0.647^{* * *}$ & 0.133 \\
\hline Financial Constraints & 0.127 & 0.105 & $-0.653^{* *}$ & 0.311 \\
\hline Excessive economic risk & $0.649^{* * *}$ & 0.090 & $0.610^{* * *}$ & 0.090 \\
\hline Lack of qualified employees & $0.571^{* * *}$ & 0.093 & $0.541^{* * *}$ & 0.092 \\
\hline Innovation costs too high & $0.358^{* * *}$ & 0.089 & $0.340^{* * *}$ & 0.086 \\
\hline Excessive get-out clause & $-1.117^{* * *}$ & 0.265 & $-1.056^{* * *}$ & 0.244 \\
\hline Lack of knowledge about financing & $0.370^{*}$ & 0.221 & 0.334 & 0.212 \\
\hline 11 Industry dummies & misc & & misc & \\
\hline \multicolumn{5}{|l|}{ Financial Constraint Equation } \\
\hline Constant & $-0.868^{* * *}$ & 0.243 & $-0.814^{* * *}$ & 0.241 \\
\hline Size & -0.054 & 0.067 & -0.013 & 0.073 \\
\hline Collateral amount & 0.067 & 0.047 & 0.035 & 0.050 \\
\hline Banking debt ratio & $0.010^{* * *}$ & 0.002 & $0.010^{* * *}$ & 0.002 \\
\hline Own financing ratio & $-0.003^{* *}$ & 0.001 & $-0.003^{* * *}$ & 0.001 \\
\hline Profit margin & $-0.007^{* * *}$ & 0.002 & $-0.008^{* * *}$ & 0.002 \\
\hline 11 industry dummies & misc & & misc & \\
\hline $\operatorname{corr}_{12}$ & & & $-0.448^{* * *}$ & 0.171 \\
\hline Log lik Innovation & \multicolumn{2}{|l|}{-965.4} & & \\
\hline Log lik Fin Constraint & \multicolumn{2}{|l|}{-803.7} & & \\
\hline Log lik Bivariate & & & -1766 & \\
\hline
\end{tabular}


Table 2.b

Innovation and Financing Constraints Joint Probit

Without Reverse Interaction Effects

(Potentially innovative firms, nobs=1082)

\begin{tabular}{|c|c|c|c|c|}
\hline \multirow{3}{*}{ Innovation Equation } & \multicolumn{2}{|c|}{ Single Equations } & \multicolumn{2}{|c|}{ Bivariate Probits } \\
\hline & \multirow[t]{2}{*}{ Coeff. } & \multirow[t]{2}{*}{ Std. } & \multirow[t]{2}{*}{ Coeff. } & \multirow[t]{2}{*}{ Std. } \\
\hline & & & & \\
\hline Constant & $-0.879^{* *}$ & 0.356 & -0.292 & 0.388 \\
\hline Size & $0.283^{* * *}$ & 0.058 & $0.232^{* * *}$ & 0.060 \\
\hline Market share & $0.698^{* *}$ & 0.295 & $0.643^{* * *}$ & 0.240 \\
\hline TP4 & $1.343^{* * *}$ & 0.249 & $1.210^{* * *}$ & 0.238 \\
\hline TP3 & $0.871^{* * *}$ & 0.203 & $0.766^{* * *}$ & 0.188 \\
\hline TP2 & $0.431^{* *}$ & 0.197 & $0.363^{* *}$ & 0.179 \\
\hline Financial Constraints & $-0.415^{* * *}$ & 0.109 & $-1.290^{* * *}$ & 0.269 \\
\hline Excessive economic risk & -0.130 & 0.099 & -0.127 & 0.094 \\
\hline Lack of qualified employees & -0.070 & 0.100 & -0.060 & 0.095 \\
\hline Innovation costs too high & $-0.417^{* * *}$ & 0.098 & $-0.381^{* * *}$ & 0.095 \\
\hline Excessive get-out clause & -0.268 & 0.259 & -0.246 & 0.243 \\
\hline Lack of knowledge about financing & 0.356 & 0.220 & 0.315 & 0.192 \\
\hline 11 Industry dummies & misc & & misc & \\
\hline \multicolumn{5}{|l|}{ Financial Constraint Equation } \\
\hline Constant & 0.458 & 0.417 & 0.457 & 0.410 \\
\hline Size & $-0.150^{*}$ & 0.081 & -0.102 & 0.084 \\
\hline Collateral amount & 0.069 & 0.058 & 0.033 & 0.059 \\
\hline Banking debt ratio & 0.007 & 0.004 & $0.007^{*}$ & 0.004 \\
\hline Own financing ratio & $-0.007^{*}$ & 0.004 & $-0.007^{* *}$ & 0.003 \\
\hline Profit margin & $-0.012^{* * *}$ & 0.002 & $-0.012^{* * *}$ & 0.002 \\
\hline 11 industry dummies & misc & & misc & \\
\hline $\operatorname{corr}_{12}$ & & & $0.574^{* * *}$ & 0.170 \\
\hline Log lik Innovation & \multicolumn{2}{|l|}{-488.8} & & \\
\hline Log lik Fin Constraint & \multicolumn{2}{|l|}{-599.2} & & \\
\hline Log lik Bivariate & & & -1083.0 & \\
\hline
\end{tabular}




\section{The Traditional Approach to Coherency Condi- tions}

To maintain the logical consistency of the model (known in the literature as "coherency") $y_{1}^{*}$ should not depend on $y_{2}^{*}$ if $y_{2}^{*}$ depends on $y_{1}^{*}$ and vice-versa.

Let us use a slightly more complicated simultaneous LDV model to illustrate the issue of coherency, namely the binary $\&$ trinomial ordered probit model of Hajivassiliou and Ioannides (2007) that studies interactions between liquidity and employment constraints on individual households indexed by $i$ at a given point in time indexed by $t$. Define two latent dependent variables $y_{1 i t}^{*}$ and $y_{2 i t}^{*}$ and drop the $i t$ subscripts:

$$
\begin{gathered}
S=\left\{\begin{array}{ccc}
1 & \text { if } & y_{1}^{*}>0 \text { (liquidity constraint binding), } \\
0 & \text { if } & y_{1}^{*} \leq 0 \text { (liquidity constraint not binding) } .
\end{array}\right. \\
E=\left\{\begin{array}{ccc}
-1 & \text { if } & y_{2}^{*} \leq \lambda^{-} \text {(overemployed) } \\
0 & \text { if } & \lambda^{-} \leq y_{2}^{*}<\lambda^{+} \text {(voluntarily employed) } \\
+1 & \text { if } & \lambda^{+} \leq y_{2}^{*} \text { (under-/unemployed) }
\end{array}\right. \\
y_{1}^{*}=\mathbf{1}\left(y_{2}^{*}<\lambda^{-}\right) \gamma_{11}+\mathbf{1}\left(\lambda^{-}<y_{2}^{*}<\lambda^{+}\right) \gamma_{12}+x_{1}^{\prime} \beta_{1}+\epsilon_{1}
\end{gathered}
$$

Since $(S, E)$ lie in $\{0,1\} \times\{-1,0,1\}$, the 6 possible configurations may be enumerated as follows:

\begin{tabular}{|l|l|l|l|}
\hline$S$ & $E$ & $y_{1}^{*}$ & $y_{2}^{*}$ \\
\hline 0 & -1 & $\gamma_{11}+x_{1} \beta_{1}+\epsilon_{1}<0$, & $x_{2} \beta_{2}+\epsilon_{2}<\lambda^{-}$ \\
\hline 0 & 0 & $x_{1} \beta_{1}+\epsilon_{1}<0$, & $\lambda^{-}<x_{2} \beta_{2}+\epsilon_{2}<\lambda^{+}$ \\
\hline 0 & +1 & $\gamma_{12}+x_{1} \beta_{1}+\epsilon_{1}<0$, & $\lambda^{+}<x_{2} \beta_{2}+\epsilon_{2}$ \\
\hline 1 & -1 & $\gamma_{11}+x_{1} \beta_{1}+\epsilon_{1}>0$, & $\delta+x_{2} \beta_{2}+\epsilon_{2}<\lambda^{-}$ \\
\hline 1 & 0 & $x_{1} \beta_{1}+\epsilon_{1}>0$, & $\lambda^{-}<\delta+x_{2} \beta_{2}+\epsilon_{2}<\lambda^{+}$ \\
\hline 1 & +1 & $\gamma_{12}+x_{1} \beta_{1}+\epsilon_{1}>0$, & $\lambda^{+}<\delta+x_{2} \beta_{2}+\epsilon_{2}$ \\
\hline
\end{tabular}

In terms of the unobservables, the probability of a $\left(y_{1}, y_{2}\right)$ observed pair is equivalent to the probability:

$$
\left(\begin{array}{l}
a_{1} \\
a_{2}
\end{array}\right)<\left(\begin{array}{l}
\epsilon_{1} \\
\epsilon_{2}
\end{array}\right)<\left(\begin{array}{l}
b_{1} \\
b_{2}
\end{array}\right)
$$

where $\left(\epsilon_{1}, \epsilon_{2}\right)^{\prime} \sim N\left(0, \Sigma_{\epsilon}\right)$, and $a$ and $b$ are given by:

\begin{tabular}{|l|l|l|l|l|l|}
\hline$S$ & $E$ & $a_{1}$ & $a_{2}$ & $b_{1}$ & $b_{2}$ \\
\hline 0 & -1 & $-\infty$ & $-\infty$ & $-\left(\gamma_{11}+x_{1} \beta_{1}\right)$ & $\lambda^{-}-x_{2} \beta_{2}$ \\
\hline 0 & 0 & $-\infty$ & $\lambda^{-}-x_{2} \beta_{2}$ & $-x_{1} \beta_{1}$ & $\lambda^{+}-x_{2} \beta_{2}$ \\
\hline 0 & +1 & $-\infty$ & $\lambda^{+}-x_{2} \beta_{2}$ & $-\left(\gamma_{12}+x_{1} \beta_{1}\right)$ & $+\infty$ \\
\hline 1 & -1 & $-\left(\gamma_{11}+x_{1} \beta_{1}\right)$ & $-\infty$ & $+\infty$ & $\lambda^{-}-\delta-x_{2} \beta_{2}$ \\
\hline 1 & 0 & $-x_{1} \beta_{1}$ & $\lambda^{-}-\delta-x_{2} \beta_{2}$ & $+\infty$ & $\lambda^{+}-\delta-x_{2} \beta_{2}$ \\
\hline 1 & +1 & $-\left(\gamma_{12}+x_{1} \beta_{1}\right)$ & $\lambda^{+}-\delta-x_{2} \beta_{2}$ & $+\infty$ & $+\infty$ \\
\hline
\end{tabular}


Using traditional arguments, we obtain that a sufficient condition for coherency of the model is:

$$
\left(\gamma_{11}+\gamma_{12}\right) \delta=0 \text { and } \gamma_{11} \gamma_{12} \delta=0
$$

- To verify this condition, suppose $(S, E)=(0,0)$. This rules out $(S, E)=(0,-1)$ because $x_{2} \beta_{2}+\epsilon_{2}>\lambda^{-}$, and rules out $(S, E)=(1,0)$ because $x_{1} \beta_{1}+\epsilon_{1}<0$.

- But $(1,-1)$ is not ruled out if the coherency conditions do not hold, since $\gamma_{11}$ could be sufficiently negative and $\delta$ sufficiently positive to imply the $(1,-1)$ conditions.

- Similarly, the $(1,1)$ possibility cannot be ruled out in the absence of the coherency conditions, since $\gamma_{12}$ and $\delta$ can be sufficiently positive.

- Such logical inconsistencies are prevented if either (a) $\delta=0$ or (b) $\gamma_{11}$ and $\gamma_{12}$ are simultaneously 0 .

Similar considerations can be employed to establish that the traditional coherency condition for our model of financing constraints and firm innovation is:

$$
\gamma \cdot \delta=0
$$

This, of course, translates to the model (1)-(2) being recursive.

\subsection{Difficulties with the traditional approaches:}

The first difficulty is that derivations of formal conditions lack intuition, are difficult to generalize, and are sufficient but not necessary.

The second one is that in practice, non-triangular or reverse triangular cases are the most interesting.

To overcome the first difficulty, alternative ways for establishing coherency are developed here, that are both intuitive and straightforward. In addition, we show that less strict conditions are possible that in fact are more interesting in practical applications.

Regarding the second fundamental difficulty with the existing approaches, it is shown in the next Section how to establish coherency without recursiveness through the use of (a) endogeneity in terms of latent variables and/or (b) sign restrictions on model parameters. The fact that our novel approach for the first time eliminates the need to assume recursivity is quite important: recursivity corresponds to the key identifying assumption that innovation does not affect financial distress directly $(\delta=$ $0)$. On a priori grounds, this assumption seems particularly dubious since innovation may lead to more profits and thus relax financial constraints (corresponding to $\delta>$ 0 ). An alternative possibility is that innovation may lead to higher investment 
in intangible assets thus reinforcing binding financial constraints (corresponding to $\delta<0)$. Both possibilities violate the traditional coherency condition. ${ }^{7}$

\subsection{Novel Approach 1: Graphical}

Let us illustrate the first approach using the Liquidity-Employment constraints application of Hajivassiliou and Ioannides (op.cit.). Figure overleaf 1 gives the 6 possible regimes $(S \times E)=\{1,0\} \times\{-1,0,1\}$ in terms of the two latent variables $y_{1}^{*}$ and $y_{2}^{*}$ and the possible configurations in terms of parameters $\bar{\lambda}, \underline{\lambda}, \delta, \gamma_{11}$, and $\gamma_{12} \cdot y_{1}^{*}$ is on the horizontal axis and $y_{2}^{*}$ on the vertical.

The figure makes clear the role of the coherency condition (a) $\delta=0$ or (b) $\gamma_{11}=\gamma_{12}=0$ : in general, regions $R 2$ and $R 6$ exhibit double-counting (cross-hatched area), as well as a white rectangle remains which makes the six regions not mutually exhaustive. These two logical incoherencies disappear when either $\delta=0$ and/or $\gamma_{11}=\gamma_{12}=0$ hold.

\footnotetext{
${ }^{7}$ Note that throughout we expect $\gamma<0$, i.e., the higher the probability that a firm faces a binding financial constraint, the less likely it is that it is able to innovate. So the two possibilities translate to: (a) $\gamma<0, \delta>0$ and (b) $\gamma<0, \delta<0$.
} 


\subsection{Novel approach 2: DGP From First Principles}

The second approach to incoherency consists of designing a data-generating algorithm (on a computer or hypothetical) to simulate random draws from an LDV model's structure. Again let us use the Liquidity-Employment Constraints application of Hajivassiliou and Ioannides (2006) to illustrate the method. We draw $\epsilon_{1}$ and $\epsilon_{2}$ under the joint bivariate normal distribution with zero mean vector and variancecovariance matrix $\Sigma_{\epsilon}$, and given $x_{1} \beta_{1}$ and $x_{2} \beta_{2}$ attempt to generate $y_{1}^{*}$ and $y_{2}^{*}$. But this is impossible unless the coherency condition holds. If (a) $\delta=0$, then latent $y_{2}^{*}$ can be drawn, then $\operatorname{ldv} y_{2}$, which together with $\epsilon_{1}$ and $x_{1} \beta_{1}$ determines the rhs of $y_{1}^{*}$, thus allowing $y_{1}$ to be drawn.

Similarly, if (b) $\gamma_{11}=\gamma_{12}=0$, then $y_{1}^{*}$ can be drawn from the first equation based on $\epsilon_{1}$ and $x_{1} \beta_{1}$, which determines $y_{1}$, thus giving $y_{2}^{*}$ and hence $y_{2}$.

This approach is related to the Gourieroux et al. (1981) condition that a function exist from $\epsilon_{1}, \epsilon_{2}$ to $y_{1}, y_{2}$. It is also related to Lewbel (2005) in that coherency translates to there being a valid reduced form for the endogenous variables. 


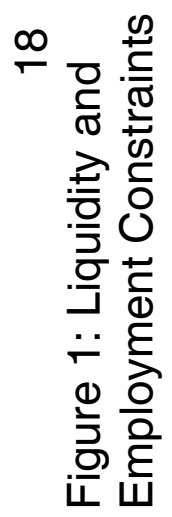
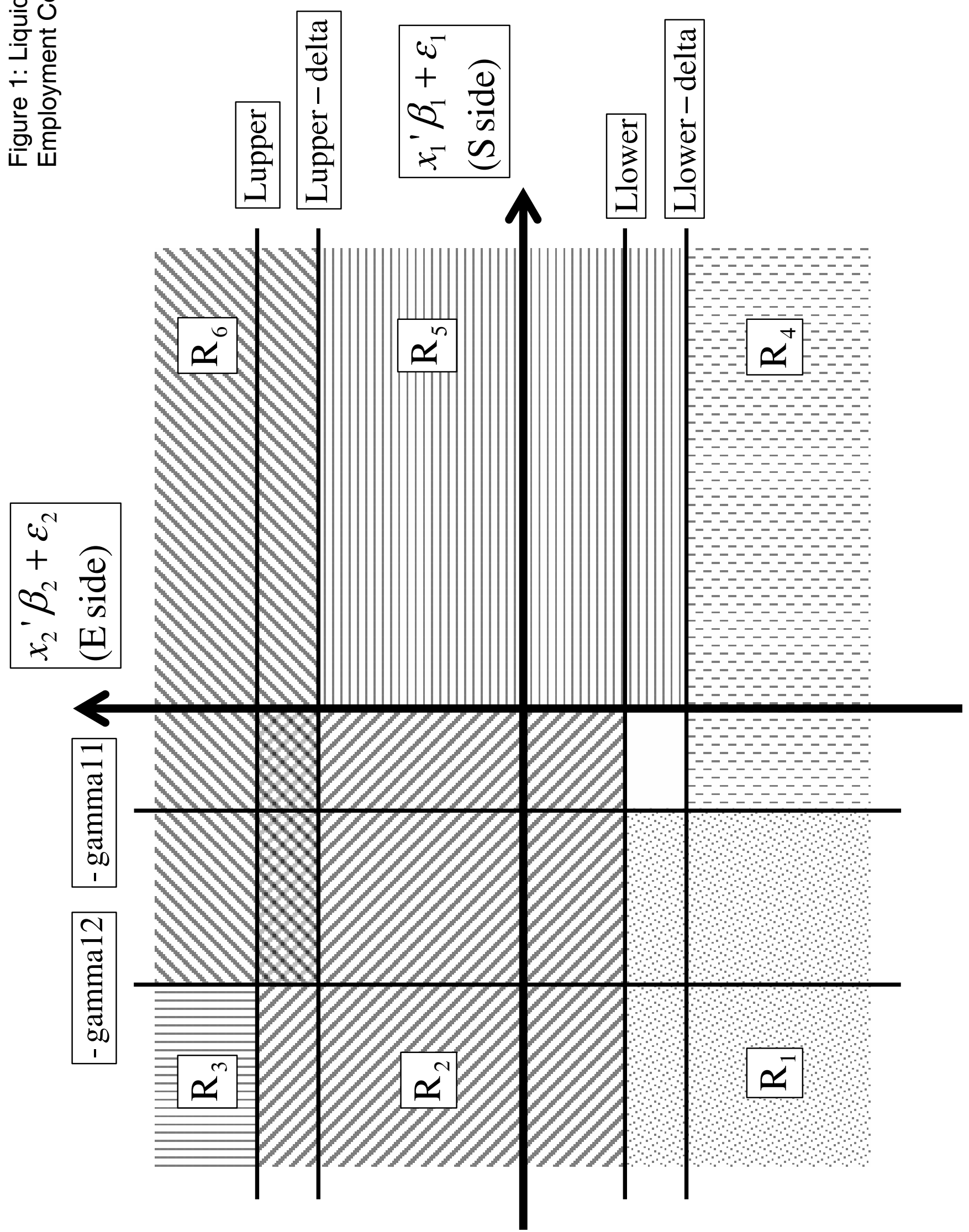


\section{Identification Under Additional Prior Sign Re- strictions}

The idea developed here is related to Uhlig (2005) whereby sign restrictions are used to achieve identification in vector autoregression macroeconomic models.

\subsection{Latent Variable Endogeneity}

$$
\begin{aligned}
& y_{1 i t}=\tau_{1}\left(y_{1 i t}^{*} \equiv\left[h_{1}\left(x_{1 i t}^{\prime} \beta_{1}, y_{2 i t}^{*} \gamma\right)+\epsilon_{1 i t}\right]\right) \\
& y_{2 i t}=\tau_{2}\left(y_{2 i t}^{*} \equiv\left[h_{2}\left(x_{2 i t}^{\prime} \beta_{2}, y_{1 i t}^{*} \delta\right)+\epsilon_{2 i t}\right]\right)
\end{aligned}
$$

Then:

$$
\begin{aligned}
& y_{1}^{*}=x_{1} \beta_{1}+y_{2}^{*} \gamma+\epsilon_{1} \\
& y_{2}^{*}=x_{2} \beta_{2}+y_{1}^{*} \delta+\epsilon_{2}
\end{aligned}
$$

and

$$
\begin{aligned}
& y_{1}^{*}=x_{1} \beta_{1}+\gamma \cdot\left[x_{2} \beta_{2}+y_{1}^{*} \delta+\epsilon_{2}\right]+\epsilon_{1} \\
& y_{2}^{*}=x_{2} \beta_{2}+\delta \cdot\left[x_{1} \beta_{1}+y_{2}^{*} \gamma+\epsilon_{1}\right]+\epsilon_{2}
\end{aligned}
$$

Hence $y_{1}^{*}=R F_{1}$ and $y_{2}^{*}=R F_{2}$, allowing us to obtain $y_{1}=\tau\left(R F_{1}\right)$ and $y_{2}=\tau\left(R F_{2}\right)$.

\subsection{Coherency through Sign Restrictions}

Illustrate with the Financing Constraints and Firm Innovation model:

$$
\begin{gathered}
I=\left\{\begin{array}{ccc}
1 & \text { if } & I^{*} \equiv x^{I} \beta^{I}+\gamma F+\epsilon^{I}>0 \\
0 & \text { otherwise }
\end{array}\right. \\
F=\left\{\begin{array}{ccc}
1 & \text { if } & F^{*} \equiv x^{F} \beta^{F}+\delta I+\epsilon^{F}>0 \\
0 & & \text { otherwise }
\end{array}\right.
\end{gathered}
$$

Four cases based on signs of $\gamma, \delta$ : 
6.2.1 Case 1: $\gamma>0, \delta>0$ - overlapping regions, incoherency 


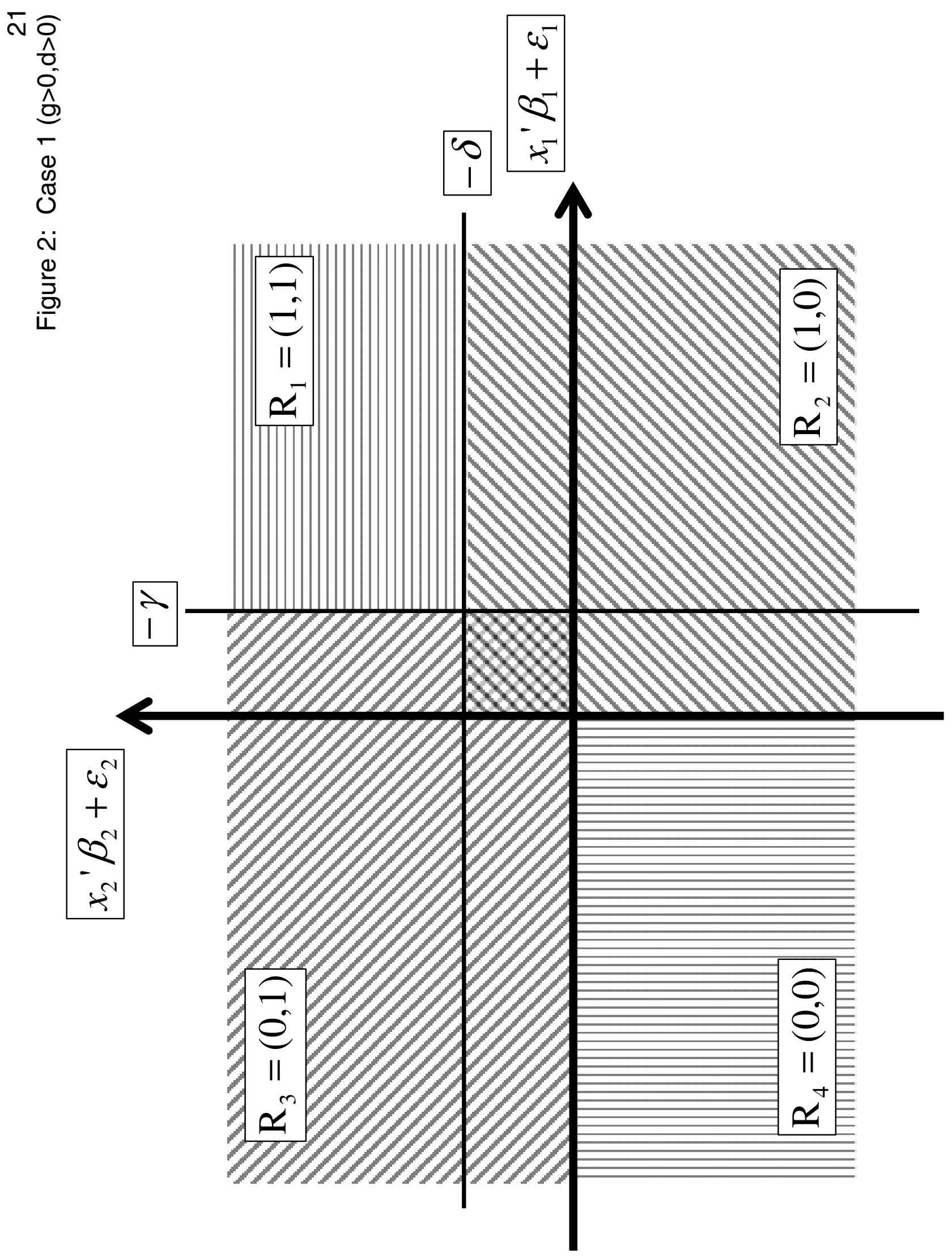


6.2.2 Case 2: $\gamma<0, \delta<0$ - overlapping regions, incoherency 


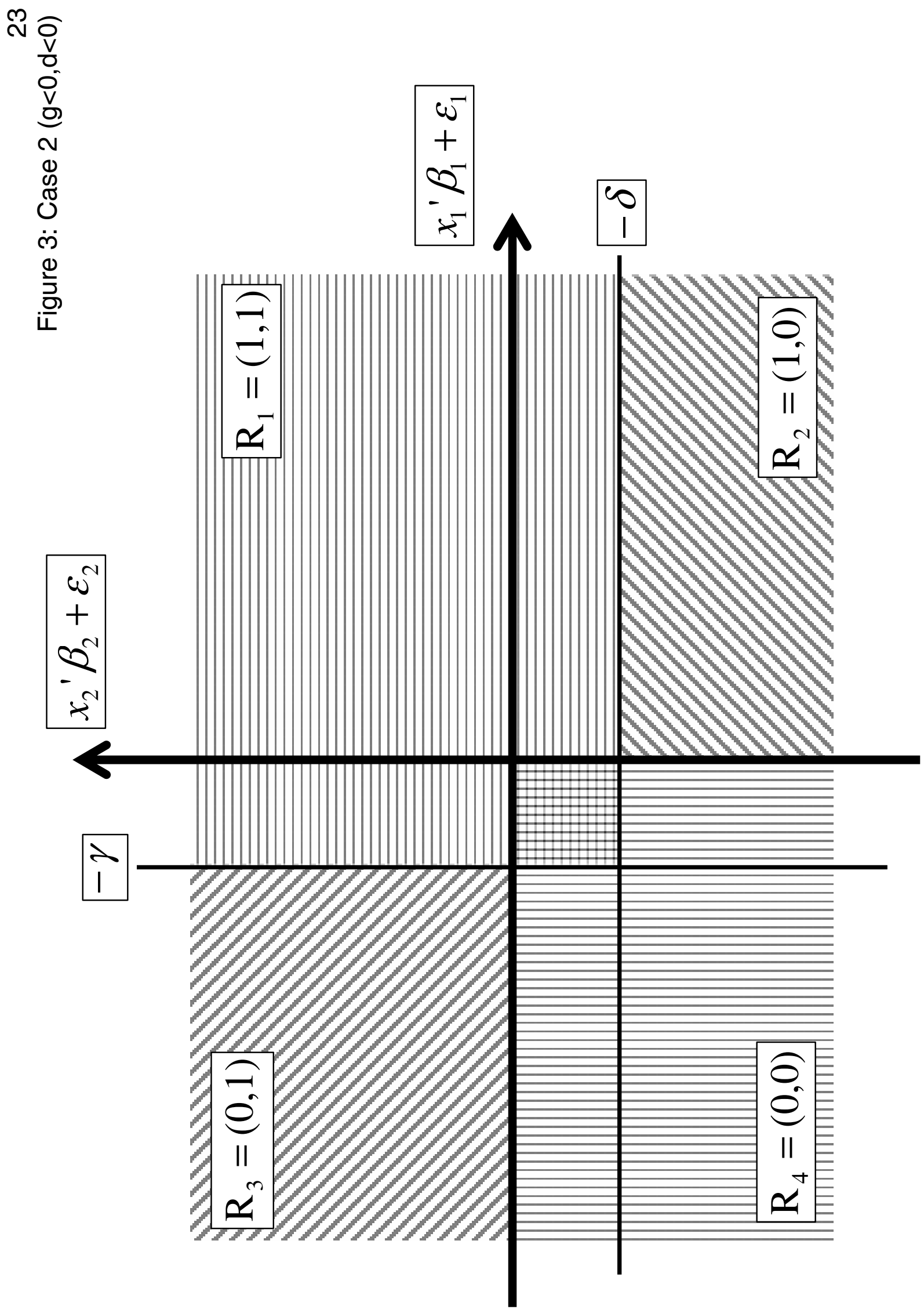


6.2.3 Case 3: $\gamma>0, \delta<0$ - empty regions, coherency through conditioning

For this case, coherency is achieved by conditioning to lie outside the "empty" region of figure 4 , which has conditioning probability:

$$
1-\operatorname{Prob}\left(-\gamma<\epsilon_{1}+x_{1} \beta_{1}<0,0<\epsilon_{2}+x_{2} \beta_{2}<-\delta\right)
$$




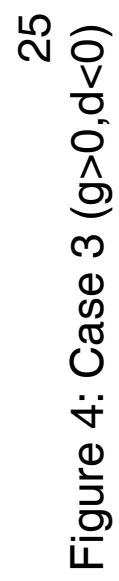

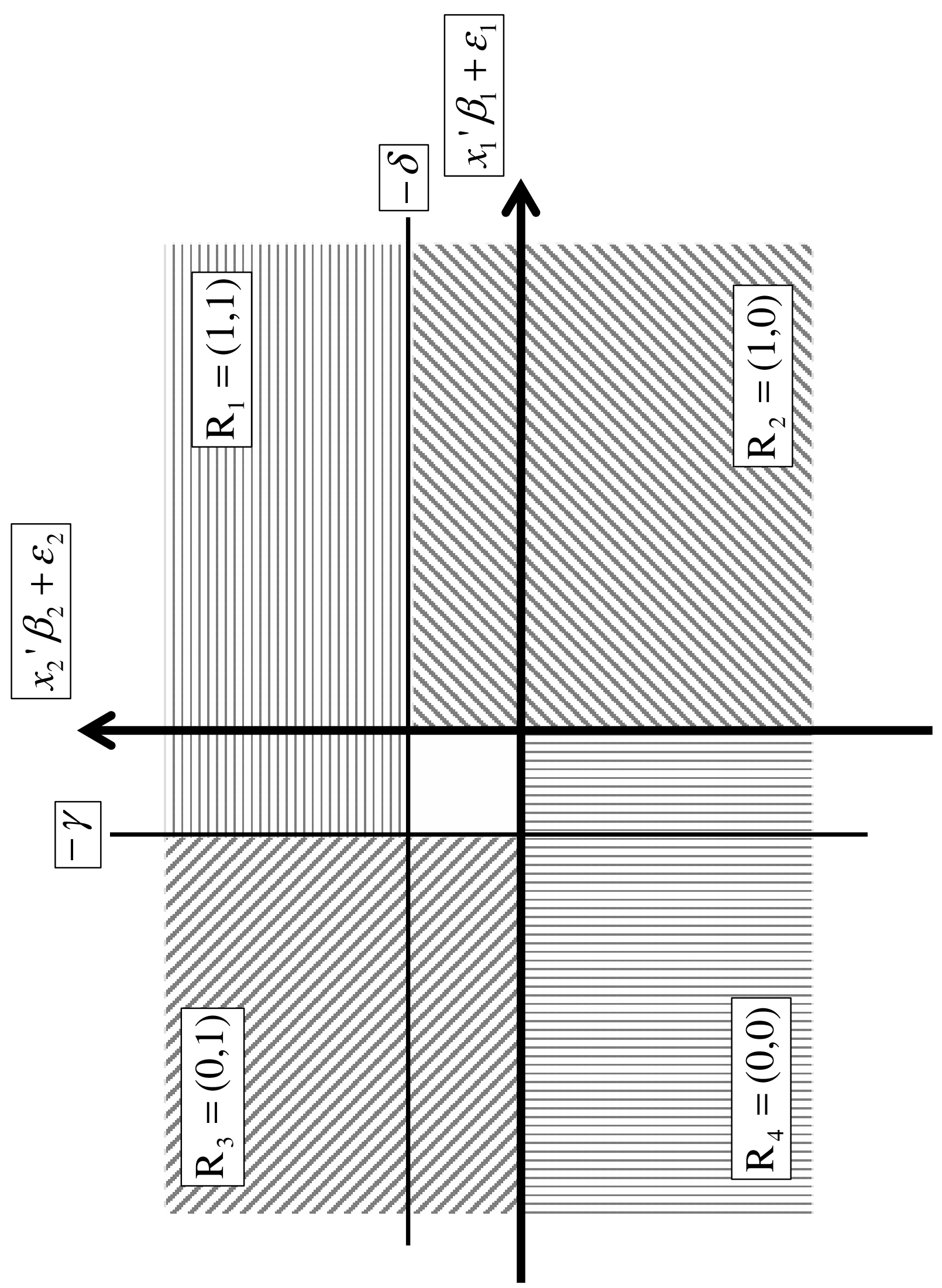




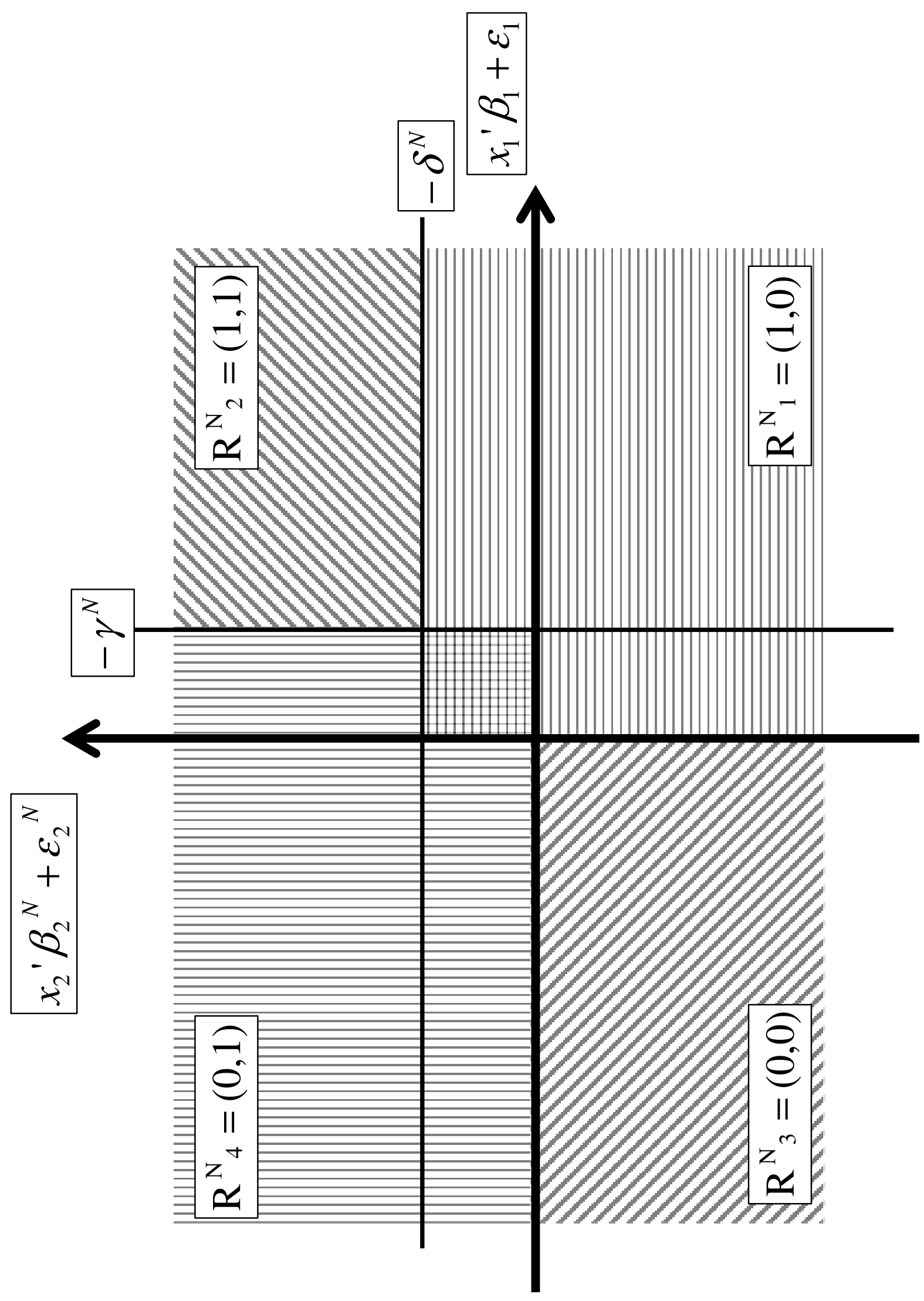


6.2.4 Case 4: $\gamma<0, \delta>0$ - empty regions, coherency through conditioning

For this case, coherency is achieved by conditioning to lie outside the "empty" region of figure 5 , which has conditioning probability:

$$
1-\operatorname{Prob}\left(0<\epsilon_{1}+x_{1} \beta_{1}<-\gamma, \delta<\epsilon_{2}+x_{2} \beta_{2}<0\right)
$$




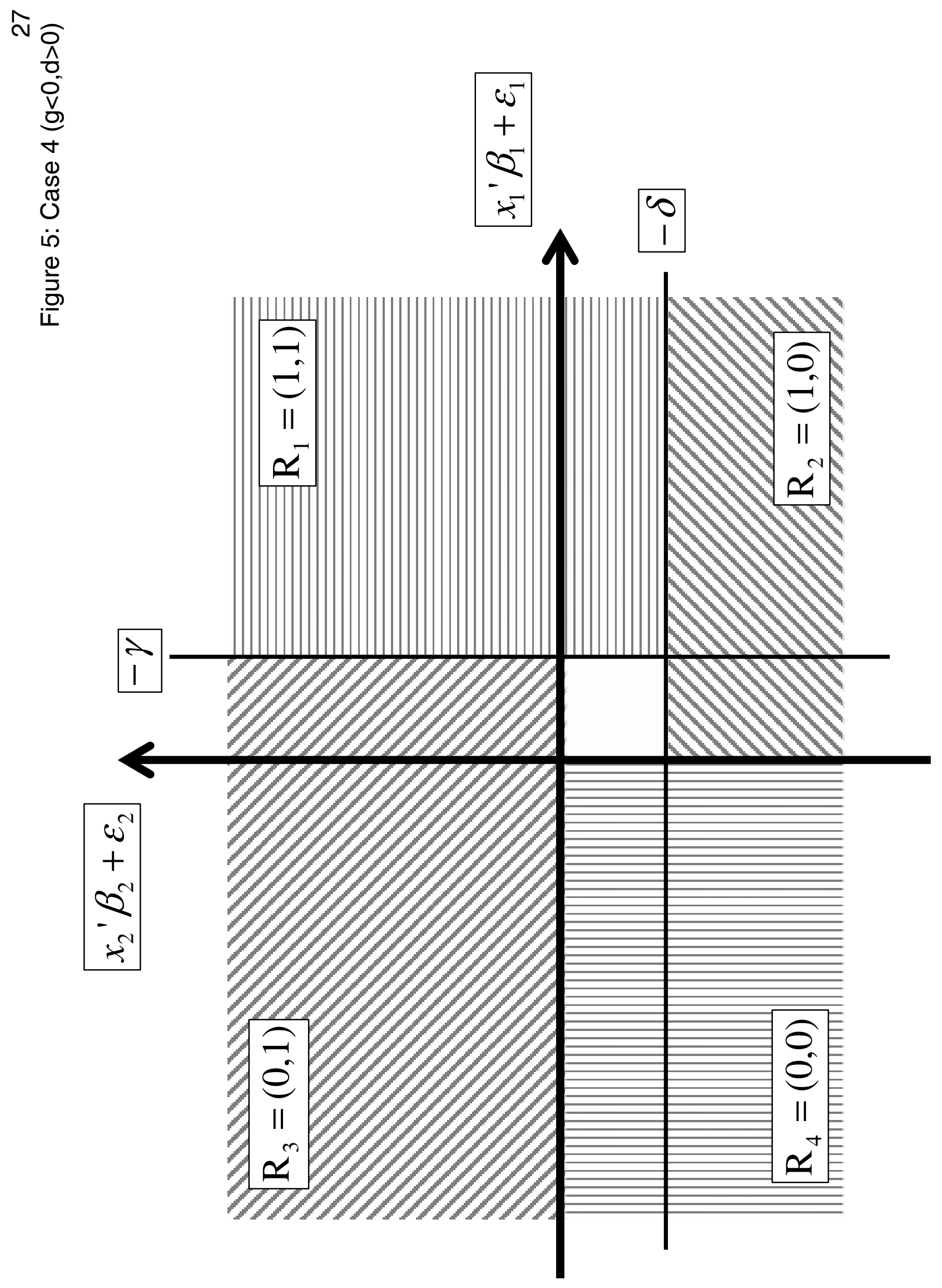




\subsection{To Show Overlapping Regions Remain Incoherent Irre- spective of LDV Definitions}

At this point, a researcher might be tempted to suggest that the incoherency cases with overlapping regions (Cases 1 and 2 above) could be overcome by redefining one of the two limited dependent variables to their complement. According to this reasoning, since the incoherency is caused in these cases because $\gamma$ and $\delta$ are of the same sign, and since changing $y_{2}$, say, to its complement $y_{2}^{N} \equiv\left(1-y_{2}\right)$ would result in $\delta^{N} \equiv-\delta$, then coherency would be achieved since then $\gamma \cdot \delta^{N}<0$.

Such reasoning would be incorrect, however. Section 7.7 in Hajivassiliou (2007) analyzes this idea and shows that such a redefinition would maintain the overlappingregion incoherency. This is because the $y_{2}^{N} \equiv\left(1-y_{2}\right)$ redefinition would also switch the sign of $\gamma$ and hence $\gamma^{N} \cdot \delta^{N}>0$ just as $\gamma \cdot \delta>0$.

\section{Monte-Carlo Experiments}

As we showed in the previous section, we obtain a coherent non-recursive model with interaction dummies included on both sides, provided we believe the feedback terms have opposite signs on the two sides. As explained already, note that it is sufficient to consider only the $\gamma \geq 0, \delta \leq 0$ case, since the reverse can always be subsumed by redefining the dependent binary variables to their complements $y_{i t}^{\prime} \equiv\left(1-y_{i t}\right)$.

The Monte Carlo summarized in this Section illustrate the consequences of adopting the following estimation approaches:

(a) Incorrectly forcing the old coherency condition to hold, i.e., assuming recursivity when in fact both feedback terms are present (estimators E-TRWN=assuming $\delta=0$ and $\mathrm{E}-\mathrm{TRNW}=$ assuming $\gamma=0) ;^{8}$

(b) unrestricted likelihood estimation, which ignores the resulting incoherency due to the empty or overlap region(s) (estimator E-INCO);

(c) restricted likelihood estimation conditioning on the data lying outside the empty region(s) of incoherency (estimators $\mathrm{E}-\mathrm{SQPM}=\operatorname{assuming}(\gamma \geq 0, \delta \leq 0)$ and $\mathrm{E}-\mathrm{SQMP}=\operatorname{assuming}(\gamma \leq 0, \delta \geq 0))^{9}$;

(d) restricted likelihood estimation conditioning on the data lying outside the overlap region(s) of incoherency (estimators $\mathrm{E}-\mathrm{SQPM}=\operatorname{assuming}(\gamma \geq 0, \delta \geq 0)$ and E-SQMP $=$ assuming $(\gamma \leq 0, \delta \leq 0))$

We generate six "true" models:

- DGP-TRWN $(\delta=0) ;^{10}$

8 "E-TRWN", stands for "Estimator-TRiangular system With interaction in first equation, No interaction in the second" and "E-TRNW", analogously.

9 "E-SQMP" corresponds to Estimator-Simultaneous Minus gamma, Plus delta and E-SQPM analogously.

${ }^{10} \mathrm{DGP}-\mathrm{xyz}$ as in E-xyz, except true Data-Generating-Process is xyz instead of Estimator assuming xyz data. 
- DGP-TRNW $(\gamma=0)$;

- DGP-SQPM $(\gamma \geq 0, \delta \leq 0)$;

- DGP-SQMP $(\gamma \leq 0, \delta \geq 0)$;

- DGP-SQPP $(\gamma \geq 0, \delta \geq 0)$; and

- DGP-SQMM $(\gamma \leq 0, \delta \leq 0)$,

and in each case, calculate the seven estimators E-TRWN, E-TRNW, E-INCO, E-SQPM, E-SQMP, E-SQPP and., E-SQMM.

The detailed methods for generating data from the each of the specified DGPs can be found in the Technical Appendix below.

These experiments confirm that our conditional likelihood approach under sign restrictions provides reliable, consistent and efficient estimates of the underlying parameters including the two interaction terms. In contrast, the existing traditional approaches (unrestricted MLE ignoring possible incoherency and MLE that incorrectly assumes recursivity of the system) give seriously misleading and inconsistent results. The reader is referred to Hajivassiliou (2007) for extensive Monte Carlos along the lines of this Section and their detailed analysis.

\section{Empirical Results Establishing Reverse Interac- tion Effects}

Using the econometric machinery we developed above that allows us to estimate joint binary probit equations with interaction terms on both sides, we present in Tables 3a and $3 \mathrm{~b}$ the application of those methods to the key issue of Being Innovative vs. Binding Financing Constraints interactions. Our final estimates in the second columns of each table confirm our expectations on a priori grounds, as well as the Monte Carlo findings summarized in the previous section: a firm undertaking actively innovative activities raises significantly the probably of it encountering a binding financing constraint, possibly because potential lenders are particularly wary of granting loans to firms of such type because of the extra riskiness involved. The effect is stronger for the full sample of firms, presumably because the greater homogeneity of the potentially innovative firms subsample dampens the impact of this interaction. The inclusion of interaction terms in both sides results in a lowering of the significance of the estimated correlation coefficients in the unobservables of the two sides, which is reassuring. Our findings should act as a strong warning to researchers in this field who employ traditional methods that either ignore or incorporate inappropriately the model coherency issue: the resulting estimation biases from such practices appear very serious indeed. 
Table 3.a

Innovation and Financing Constraints Joint Probit

With Reverse Interaction Effects (full sample, nobs=1940)

\begin{tabular}{|c|c|c|c|c|}
\hline \multirow{3}{*}{ Innovation equation } & \multicolumn{2}{|c|}{ Single Equations } & \multicolumn{2}{|c|}{ Bivariate Probits } \\
\hline & \multirow[t]{2}{*}{ Coeff. } & \multirow[t]{2}{*}{ Std. } & \multirow[t]{2}{*}{ Coeff. } & \multirow[t]{2}{*}{ Std. } \\
\hline & & & & \\
\hline Constant & $-2.731^{* * *}$ & 0.225 & $-7.235^{* * *}$ & 0.118 \\
\hline Size & $0.304^{* * *}$ & 0.034 & $0.183^{* * *}$ & 0.020 \\
\hline Market share & 0.025 & 0.063 & 0.020 & 0.045 \\
\hline $\mathrm{TP} 4$ & $1.646^{* * *}$ & 0.165 & $1.822^{* * *}$ & 0.183 \\
\hline TP3 & $1.086^{* * *}$ & 0.132 & $1.0110^{* * *}$ & 0.199 \\
\hline TP2 & $0.684^{* * *}$ & 0.128 & $0.437^{* * *}$ & 0.176 \\
\hline Financial Constraints & 0.127 & 0.105 & $-0.324^{* *}$ & 0.255 \\
\hline Excessive economic risk & $0.649^{* * *}$ & 0.090 & $0.550^{* * *}$ & 0.070 \\
\hline Lack of qualified employees & $0.571^{* * *}$ & 0.093 & $0.431^{* * *}$ & 0.081 \\
\hline Innovation costs too high & $0.358^{* * *}$ & 0.089 & $0.233^{* * *}$ & 0.072 \\
\hline Excessive get-out clause & $-1.117^{* * *}$ & 0.265 & $-1.022^{* * *}$ & 0.145 \\
\hline Lack of knowledge about financing & $0.370^{*}$ & 0.221 & 0.221 & 0.133 \\
\hline 11 Industry dummies & $\operatorname{misc}$ & & misc & \\
\hline \multicolumn{5}{|l|}{ Financial Constraint Equation } \\
\hline Constant & $-0.868^{* * *}$ & 0.243 & $-1.221^{* * *}$ & 0.241 \\
\hline Firm Innovates & & & $0.647^{* * *}$ & 0.032 \\
\hline Size & -0.054 & 0.067 & -0.016 & 0.073 \\
\hline Collateral amount & 0.067 & 0.047 & 0.030 & 0.050 \\
\hline Banking debt ratio & $0.010^{* * *}$ & 0.002 & $0.015^{* * *}$ & 0.002 \\
\hline Own financing ratio & $-0.003^{* *}$ & 0.001 & $-0.001^{* * *}$ & 0.001 \\
\hline Profit margin & $-0.007^{* * *}$ & 0.002 & $-0.002^{* * *}$ & 0.002 \\
\hline 11 industry dummies & $\operatorname{misc}$ & & misc & \\
\hline $\operatorname{corr}_{12}$ & & & $-0.132 * * *$ & 0.013 \\
\hline Log lik Innovation & \multicolumn{2}{|l|}{-965.4} & & \\
\hline Log lik Fin Constraint & \multicolumn{2}{|l|}{-803.7} & & \\
\hline Log lik Bivariate & & & -1712 & \\
\hline
\end{tabular}




\section{Table 3.b}

Innovation and Financing Constraints Joint Probit

With Reverse Interaction Effects

(Potentially innovative firms, nobs $=1082$ )

\begin{tabular}{|c|c|c|c|c|}
\hline \multirow{3}{*}{ Innovation Equation } & \multicolumn{2}{|c|}{ Single Equations } & \multicolumn{2}{|c|}{ Bivariate Probits } \\
\hline & \multirow[t]{2}{*}{ Coeff. } & \multirow{2}{*}{ Std. } & \multirow[t]{2}{*}{ Coeff. } & \multirow[t]{2}{*}{ Std. } \\
\hline & & & & \\
\hline Constant & $-0.879^{* *}$ & 0.356 & -0.292 & 0.388 \\
\hline Size & $0.283^{* * *}$ & 0.058 & $0.232^{* * *}$ & 0.060 \\
\hline Market share & $0.698^{* *}$ & 0.295 & $0.643^{* * *}$ & 0.240 \\
\hline $\mathrm{TP} 4$ & $1.343^{* * *}$ & 0.249 & $1.210^{* * *}$ & 0.238 \\
\hline TP3 & $0.871^{* * *}$ & 0.203 & $0.766^{* * *}$ & 0.188 \\
\hline TP2 & $0.431^{* *}$ & 0.197 & $0.363^{* *}$ & 0.179 \\
\hline Financial Constraints & $-0.415^{* * *}$ & 0.109 & $-1.290^{* * *}$ & 0.269 \\
\hline Excessive economic risk & -0.130 & 0.099 & -0.127 & 0.094 \\
\hline Lack of qualified employees & -0.070 & 0.100 & -0.060 & 0.095 \\
\hline Innovation costs too high & $-0.417^{* * *}$ & 0.098 & $-0.381^{* * *}$ & 0.095 \\
\hline Excessive get-out clause & -0.268 & 0.259 & -0.246 & 0.243 \\
\hline Lack of knowledge about financing & 0.356 & 0.220 & 0.315 & 0.192 \\
\hline 11 Industry dummies & $\operatorname{misc}$ & & $\operatorname{misc}$ & \\
\hline \multicolumn{5}{|l|}{ Financial Constraint Equation } \\
\hline Constant & 0.458 & 0.417 & 0.467 & 0.410 \\
\hline Firm Innovates & & & $0.324^{* * *}$ & 0.133 \\
\hline Size & $-0.150^{*}$ & 0.081 & -0.099 & 0.084 \\
\hline Collateral amount & 0.069 & 0.058 & 0.030 & 0.059 \\
\hline Banking debt ratio & 0.007 & 0.004 & $0.004^{*}$ & 0.004 \\
\hline Own financing ratio & $-0.007^{*}$ & 0.004 & $-0.003^{* *}$ & 0.003 \\
\hline Profit margin & $-0.012^{* * *}$ & 0.002 & $-0.077^{* * *}$ & 0.002 \\
\hline 11 industry dummies & misc & & misc & \\
\hline $\operatorname{corr}_{12}$ & & $0.254^{* * *}$ & 0.150 \\
\hline Log lik Innovation & \multicolumn{2}{|l|}{-488.8} & & \\
\hline Log lik Fin Constraint & \multirow{2}{*}{\multicolumn{2}{|c|}{-599.2}} & & \\
\hline Log lik Bivariate & & & -1067.9 & \\
\hline
\end{tabular}




\section{State Dependence in Financing and Innovation Experiences of Firms}

We now explain how the nature of the available datasets can be exploited to study whether, ceteris paribus, past financial distress or innovation failures can affect a firm's current experiences in these two dimensions.

Though the datasets we use are not truly longitudinal, "panel" sets, the CIS part of the information we use was collected in four biennial waves. Hence, we know whether a particular firm $i$ has reported binding financing constraints in the past. Similarly, we can also tell whether a firm has failed in the past in its efforts to be innovative. Consequently, though our dataset is not a true panel, we can extend our econometric equations modelling the probabilities of being innovative and of encountering binding financing constraints at the end of the sample period to condition also on past experiences in these two dimensions. The results of these investigations are currently under preparation. ${ }^{11}$ The table that follows gives the transition matrix between the four regimes $\left(I_{i t}, F_{i t}\right)=\{(1,1),(1,0),(0,1),(0,0)\}$ from the early period covered by the CIS (1994-6) to the later one covered by the FIT (19979 ). These transitions confirm the importance of dynamics in the joint analysis of binding financing constraints and firm innovation. Detailed econometric estimations that include state dependence terms on both sides of our model are currently under preparation. The preliminary findings confirm the very strong importance of such terms.

\footnotetext{
${ }^{11}$ CIS4, covering the 2002-2004 is forthcoming presently.
} 
TABLE 4A: Innov Transitions 1994-6 -> 1997-9

\begin{tabular}{|c|c|c|c|c|}
\hline & \multicolumn{3}{|c|}{ 1997-1999 (FIT) } \\
\hline & & $I_{i t}=1$ & $I_{i t}=0$ & Total \\
\hline \multirow{9}{*}{ 1994-1996 } & \multirow{3}{*}{$I_{i, t-1}=1$} & 84.45 & 40.74 & 42.53 \\
\hline & & 543 & 354 & 897 \\
\hline & & 60.54 & 39.46 & 100 \\
\hline & \multirow{3}{*}{$I_{i, t-1}=0$} & 15.55 & 59.26 & 57.47 \\
\hline & & 100 & 515 & 615 \\
\hline & & 16.26 & 83.74 & 100 \\
\hline & \multirow{3}{*}{ Total } & 100 & 100 & 100 \\
\hline & & 643 & 869 & 1512 \\
\hline & & 42.53 & 57.47 & 100 \\
\hline
\end{tabular}

TABLE 4B: FinCons Transitions 1994-6 -> 1997-9

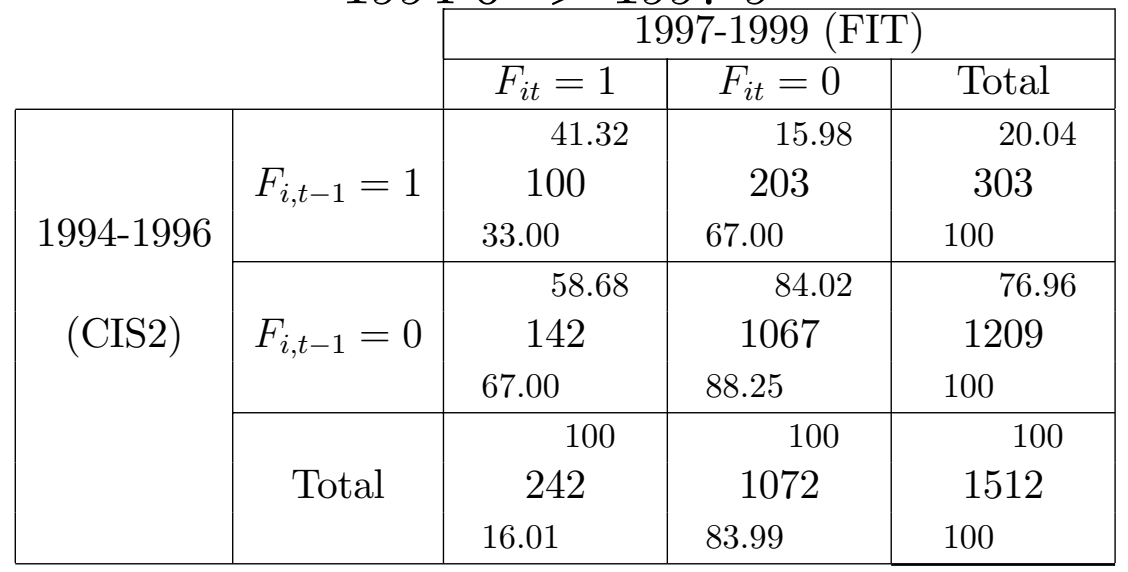

Legend: $\begin{gathered}\text { col \% } \\ \text { Cell } \\ \text { Count } \\ \text { row } \%\end{gathered}$


TABLE 4C: 1994-6 -> 1997-9 Transitions

\begin{tabular}{|c|c|c|c|c|c|c|}
\hline & & \multicolumn{5}{|c|}{ 1997-1999 (FIT) } \\
\hline & & $\begin{array}{c}I_{i t}=1 \\
\text { and } \\
F_{i t}=1\end{array}$ & $\begin{array}{c}I_{i t}=1 \\
\text { and } \\
F_{i t}=0\end{array}$ & $\begin{array}{c}I_{i t}=0 \\
\text { and } \\
F_{i t}=1\end{array}$ & $\begin{array}{c}I_{i t}=0 \\
\text { and } \\
F_{i t}=0\end{array}$ & Total \\
\hline \multirow{5}{*}{$\begin{array}{c}\text { 1994-1996 } \\
\text { (CIS2) }\end{array}$} & $\begin{array}{c}I_{i, t-1}=1 \\
\text { and } \\
F_{i, t-1}=1\end{array}$ & $\begin{array}{r}15.8 \\
7^{7} \\
37.6\end{array}$ & $\begin{array}{c}37.7 \\
5^{5} \\
28.3\end{array}$ & $\begin{array}{l}14.8 \\
13 \\
6.3^{1}\end{array}$ & $\begin{array}{c}{ }^{7.3} \\
57^{7} \\
27.8\end{array}$ & $\begin{array}{l}13.6 \\
205 \\
100\end{array}$ \\
\hline & $\begin{array}{c}I_{i, t-1}=1 \\
\text { and } \\
F_{i, t-1}=0\end{array}$ & $\begin{array}{l}68.9 \\
337 \\
48.7\end{array}$ & $\begin{array}{l}46.1 \\
{ }^{71} \\
10.3\end{array}$ & $\begin{array}{l}30.7 \\
2^{27} \\
3.9\end{array}$ & $\begin{array}{l}32.9 \\
257 \\
37.1\end{array}$ & $\begin{array}{l}45.8 \\
692 \\
100\end{array}$ \\
\hline & $\begin{array}{l}I_{i, t-1}=0 \\
\text { and } \\
F_{i, t-1}=1\end{array}$ & $7^{7.1} 7^{1.4}$ & $\begin{array}{c}12^{7.8} \\
12.2^{-1}\end{array}$ & $\begin{array}{c}19.3 \\
17 \\
17.3\end{array}$ & $\begin{array}{c}{ }^{7.9} \\
62^{2} \\
63.3^{2}\end{array}$ & $\begin{array}{l}{ }^{6.5} \\
98^{6} \\
100\end{array}$ \\
\hline & $\begin{array}{l}I_{i, t-1}=0 \\
\text { and } \\
F_{i, t-1}=0\end{array}$ & $\begin{array}{l}13.9 \\
68 \\
13.2\end{array}$ & $\begin{array}{c}{ }^{8.4} \\
13 \\
2.5\end{array}$ & $\begin{array}{l}35.2 \\
31 \\
6.0\end{array}$ & $\begin{aligned} & 51.9 \\
& 405 \\
& 78.3\end{aligned}$ & $\begin{array}{l}34.2 \\
517 \\
100\end{array}$ \\
\hline & Total & $\begin{array}{l}100 \\
489 \\
32.3\end{array}$ & $\begin{array}{l}100 \\
154 \\
10.2\end{array}$ & $\begin{array}{l}{ }^{100} \\
88^{100} \\
5.8\end{array}$ & $\begin{array}{l}100 \\
781 \\
51.7\end{array}$ & $\begin{array}{l}100 \\
1512 \\
100\end{array}$ \\
\hline & & Legend: & \multicolumn{2}{|c|}{ col \% } & & \\
\hline
\end{tabular}




\section{Avenues for Future Research}

In this section we outline our plans for extending the analysis of the paper in several directions.

Several ideas that we leave for future extensions of this research are the following:

First, there might exist useful additional information in the ranking of the different types of financing constraints over and above the simple binary indicator used here. For example, an ordered 3-value financing indicator might have been used instead, with the second equation being a 3-way ordered probit instead of a binary one.

Second, perhaps the size variable should enter non-linearly, e.g., through a simple quadratic or similar forms, to allow for the U-curve style of relations predicted by some theoretical models in the literature.

Thirdly, we could consider splitting the sample of innovative firms into ones who are real innovators from the ones who are merely adopters of innovative technologies and/or processes. This information will be in available in the forthcoming CIS4 survey. On a priori grounds, it appears that financiers are likely to treat these two sub-types of innovative firms as quite distinct, with concomitant differences in funding riskiness. Unfortunately, the sub-category of "potentially innovative" firms who have attempted to introduce innovations but failed may need to be dropped altogether and the consequences of doing so to be investigated, since it appears impossible to identify the reasons for such failures, in particular whether it was due to binding financial constraints or due to the innovation idea being inherently bad.

A related hypothesis we plan to analyze, which is studied preliminarily in Corres et al (2001), is that of hierarchical financing in terms of effective cost: first proceed with internal financing, and only continue with external one if the granted interest rate is low enough. The first alternative explanation explored is that the structure of types of debt are different, which would explain partially the differences in average interest rates observed. The second alternative is that innovating firms are in general of bigger size and established for longer so that they can be granted loans at lower interest rates. The third alternative explanation, which our preferred one, goes as follows: the findings are driven by a very serious selection bias, since observing a zero interest rate could mean one of three things: (a) the firm did not want any new loan; (b) the firm requested a loan but did not take one because the interest terms of the loan were too expensive; or (c) the firm requested a loan but the bank did not grant one. Along similar lines, it appears worthwhile to study explicitly the alternative mode of financing of issuing new shares for publicly quoted firms.

A further refinement we consider elsewhere is to build more detailed sequential models whereby a firm chooses whether or not to request a loan and given it decides yes, whether or not the bank grants the loan. In addition, it seems interesting to model also the final possibility that a firm may apply for a loan, the bank might grant it, but the firm might reject the offer as too costly. Assuming all the necessary data exists for building such an econometric framework, one could learn quite a lot about 
the mechanisms of these markets.

Finally, it should be noted that our econometric approach developed in this paper can be applied to the related problem of investment decisions by firms being directly affected by binding financing constraints.

\section{Conclusions}

In this paper analyzed the existence and impact of financing constraints as a possibly serious obstacle to innovation by firms. Direct measures of financing constraints were employed using survey data collected by the Banque de France, which helped us overcome the problems with the traditional approach in the past literature of trying to deduce the existence and impact of financing constraints through the significance of firm wealth variables.

We used as the main econometric framework employed for our empirical analyses the simultaneous bivariate probit with mutual endogeneity. We discussed the important identification issue of coherency conditions in such LDV models with endogeneity and flexible temporal and contemporaneous correlations in the unobservables. We argued that conditions for coherency in the existing literature are rather esoteric and instead presented two novel methods for establishing coherency conditions, one based on graphical characterizations, the second on hypothetical Monte-Carlo DGPs.

Finally, the paper developed alternative approaches for achieving coherency in models traditionally classified as incoherent through the use of prior sign restrictions on model parameters. This allowed us to obtain estimates of the interaction between financing constraints and a firm's decision and ability to innovate without forcing the model to be recursive. Thus, direct as well as reverse interaction effects were obtained for the first time. Our findings should act as a strong warning to researchers in this field who employ traditional methods that either ignore or incorporate inappropriately the model coherency issue: the resulting estimation biases from such practices appear very serious indeed. 


\section{References}

[1] Corres S, Hajivassiliou V., Ioannides Y. (2006), "An Empirical Investigation on the Dynamics of Qualitative Decisions of Firms", LSE Financial Markets Group working paper.

[2] Gourieroux C., Laffont J.J, Monfort A. (1980), "Coherency Conditions in Simultaneous Linear Equations Models with Endogenous Switching Regime", Econometrica, vol. 48 (3), pp. 75-96.

[3] Hajivassiliou V. (2007), "Novel Approaches to Coherency Conditions in LDV Models", LSE Department of Economics working paper.

[4] Hajivassiliou, V., Y. Ioannides (2007), "Unemployment and Liquidity Constraints" Journal of Applied Econometrics, vol. 22(3), pp.479-510.

[5] Hajivassiliou V., McFadden D.L. (1998), "The Method of Simulated Scores for the Estimation of LDV Models", Econometrica, vol. 66(4), pp.863-896.

[6] Jensen M.C, Meckling W.H. (1976), "Theory of the Firm : Managerial Behavior, Agency Costs and Ownership Structure", Journal of Financial Economics, pp. 305-360.

[7] Lewbel (2005), "Coherency of Structural Models Containing a Dummy Endogenous Variable", Boston College Working Papers in Economics n ${ }^{\circ} 456$.

[8] Modigliani F., Miller M. (1958), "The cost of capital, corporation finance, and the theory of investment", American Economic Review, vol. 48, pp. 261-297.

[9] Modigliani F., Miller M. (1963), "Corporate income taxes and the cost of capital: a correction", American Economic Review, vol. 53, pp. 433-443.

[10] OECD and Eurostat (1997), Oslo-Manual, Proposed Guidelines for Collecting and Interpreting Technological Innovation Data, Organization for Economic Cooperation and Development, Paris.

[11] Savignac F. (2006), Le financement des entreprises innovantes, PhD dissertation, Université Panthéon-Sorbonne (Paris 1).

[12] Savignac F. (2006), "The Impact of Financial Constraints on Innovation: Evidence from French Manufacturing Firms", Cahiers de la Maison des Sciences Economiques v06042, Université Panthéon-Sorbonne (Paris 1).

[13] Stiglitz J., Weiss A., (1981), "Credit Rationing in Markets with Imperfect Information", American Economic Review, vol. 71(3), pp. 393-410. 
[14] Uhlig H. (2005), "What are the effects of monetary policy on output? Results from an agnostic identification procedure", Journal of Monetary Economics, vol. 52(2), pp. 381-419. 


\section{Data Appendix}

We use data from two sources: a survey about the financing conditions of innovative projects for established manufacturing firms and the Banque de France Balance Sheet Data.

\subsection{The FIT survey}

We use the survey "Financement de l'Innovation Technologique" (FIT) that was conducted in 2000 by the French Ministry of Industry. Its aim was to obtain statistical information about the financing conditions of innovative projects of manufacturing firms in France. This survey allows to identify the firms which undertook innovative projects between 1997 and 1999 and it gives qualitative information about the financial constraints that firms may have experienced when planning and conducting those projects. A sample of 5500 industrial companies was surveyed. It is composed by manufacturing firms with 20 employees and more (excluding agricultural-food and building sectors). It is important to notice that start-ups and new established firms are not in the field of this survey. Globally, the rate of response amounts to $70 \%$ (Sessi 2002) so that about 3700 firms are present in the available FIT sample.

As the Community Innovation Surveys (CIS), the FIT survey is based upon the technological innovation concept exposed in the Oslo manual (OECD 1997). ${ }^{12}$ This measure of innovative activities is less restrictive than $R \& D$ expenditures or patents data. Indeed, innovative activities are not systematically associated with R\&D investments and patents are also strategic tools that are not necessarily used by firms to protect innovation.

In this paper, we are interested in identifying firms with innovative activities (and not only those that succeeded in introducing their innovation on the market).

- We qualified as "innovative" a firm that have introduced or develop a product or process innovation or that have been in process of doing so during the surveyed period. This identification of innovative firms is made thanks to their answers to the three following questions:

1) In 1997, 1998 or 1999, did Your enterprise introduce onto the market any new or significantly improved products for Your enterprise?

2) In 1997, 1998 or 1999, did Your enterprise introduce onto the market any new or significantly improved process for Your enterprise?

\footnotetext{
${ }^{12}$ The Community Innovation Surveys (CIS) are conducted in each country by the national statistical entities in order to collect information about the innovative activities of firms. In each country, they are based on the same questionnaire that may be completed by additional questions. The survey used here (Financement de l'Innovation Technologique, FIT) is different because it is focused on the financing of innovation. However, its methodological framework is the same as the well-known CIS' one, in particular concerning the definition of innovation and the structure of the questionnaire.
} 
3) In 1997, 1998 or 1999, did Your enterprise have projects of new or significantly improved products or processes:

- Which are not yet completed or not yet introduce to the market?

- Which were failures?

In other words, a firm is innovative when it answered positively to at least one of these three questions.

- The qualitative information about the obstacles to innovation is given in the last part of the questionnaire. All surveyed firms have to answer the following question:

In 1997, 1998 or 1999, what are the obstacles that have prevented your firm to conduct or to start innovative projects (multiple answers possible)?

- Excessive perceived economic risk

- Lack of qualified personnel

- Innovation costs too high

- Lack of sources of finance

- Slowness in the setting up of the financing

- Too high interest rates of the financing

- Excessive get out clause in the shareholder agreement

- Lack of knowledge about ad hoc financial networks

- No obstacle

In addition, the firm has to tick the effect of each listed hampering factors on their innovative projects: (seriously delayed, abandoned or prevented to be started). As a firm may have several innovative projects, it can mention several consequences of obstacles (for instance, both delayed and non started projects).

- We consider that a firm faced financial constraints when it answered that it has seriously delayed, abandoned or non-started projects because of:

- Too high interest rates of the financing

- Lack of sources of finance

- Slowness in the setting up of the financing

A significant part of the firms in our initial sample (44\%) answered simultaneously that they have not completed nor are in process of implementing innovative projects, and that they do not encounter any obstacle to innovation. Consequently, it could be assessed that this group of firms does not wish to innovate and thus, that those firms are not concerned by obstacles to innovation in general and by financial obstacles in particular. To try to identify the firms that wished to innovate, we define two groups of firms: 
- The potentially innovative firms are the firms that positively answered to the first three questions (i.e.. firms that introduced or developed a product or process innovation or that were in process of doing so during the surveyed period) or the non innovative firms that faced obstacles to innovation. Thus, some of those firms are innovative as defined above (they succeeded in starting, even in completing their projects) while the other ones were not able to start none of their innovative projects.

- The second type of firms (the "others") are the non innovative ones that ticked they did not face any obstacle to innovation. Consequently, it may be assessed that these firms did not wish to innovate.

\subsection{The Banque de France Balance Sheet Dataset}

In order to have more information about the surveyed firms (their size, economic performance and financing structure) we use the Banque de France Balance Sheet Dataset. ${ }^{13}$ This is a database containing essentially very detailed accounting data of French companies, obtained from their fiscal forms plus some complementary questionnaires. The database includes all businesses with more than 500 employees and a fraction of smaller firms so that the member firms amount to around 34,000 companies. It achieves an overall coverage rate of $57 \%$ in industry (in terms of number of employees). This rich database is used by the Banque de France to update knowledge of the structure and performance of the French productive system. In addition, it makes it possible for example, to pinpoint sources of financing, to isolate group financing or to identify expenditures in intangible goods and services.

\section{Our sample}

Our sample results from the matching of these two sources. We were able to recover about $60 \%$ of the FIT sample companies. After some necessary cleaning, our sample contains 1940 firms. ${ }^{14}$. The distribution of the firms in our sample according to their innovative behavior and financing obstacles is given in the table below:

\footnotetext{
${ }^{13}$ The "Centrale de bilans" dataset.

${ }^{14}$ The manufacture of coke, refined petroleum products and nuclear fuel has been deleted because only two firms were present in the merged dataset. In addition, the firms with negative value added or with abnormally high investment rates have been excluded. This concerns only two firms.
} 
Table. Number of firms in the sample

\begin{tabular}{|c|c|c|c|c|}
\hline \multicolumn{4}{|c|}{ Potentially innovative firms } & \multirow[t]{2}{*}{ Others } \\
\hline \multicolumn{2}{|c|}{ with innovative activities } & \multicolumn{2}{|c|}{ without innovative activities } & \\
\hline financially & financially & financially & financially & \\
\hline constrained & unconstrained & constrained & unconstrained & \\
\hline 198 & 613 & 112 & 159 & 858 \\
\hline
\end{tabular}

Sources : Centrale de Bilans (Banque de France), FIT (Sessi)

Table. Definition of the variables

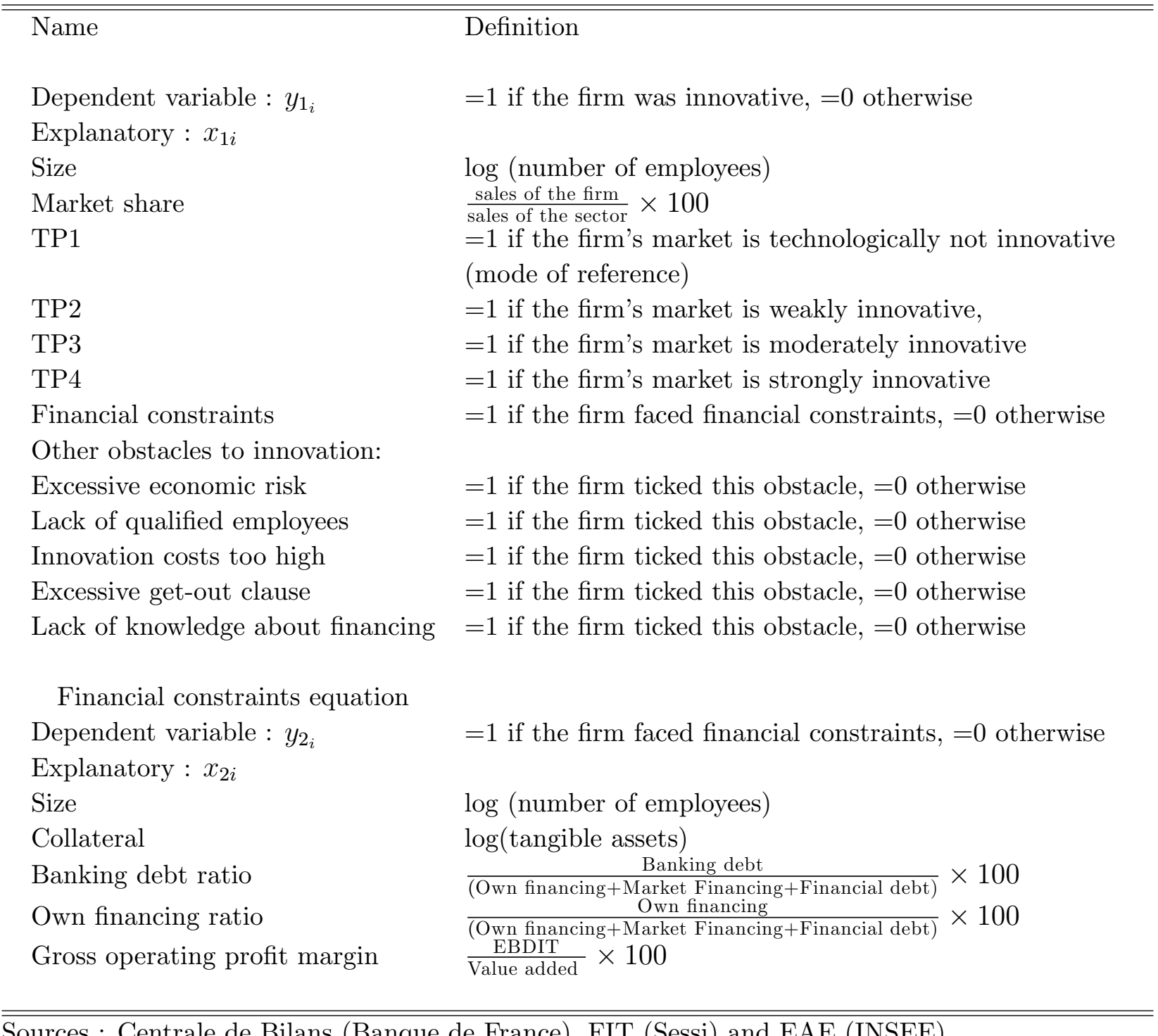

Sources : Centrale de Bilans (Banque de France), FIT (Sessi) and EAE (INSEE) 
Table. Descriptive statistics (full sample)

\begin{tabular}{lcccc}
\hline \hline & Mean & Std & Min & Max \\
Innovation & 0.418 & 0.493 & 0 & 1 \\
Size & 4.783 & 1.107 & 2.890 & 9.716 \\
Market share & 0.177 & 0.566 & 0.001 & 16.15 \\
TP1 & & & & \\
TP2 & 0.416 & 0.493 & 0 & 1 \\
TP3 & 0.348 & 0.476 & 0 & 1 \\
TP4 & 0.097 & 0.297 & 0 & 1 \\
Financial constraints & 0.160 & 0.366 & 0 & 1 \\
Excessive economic risk & 0.228 & 0.420 & 0 & 1 \\
Lack of qualified employees & 0.206 & 0.404 & 0 & 1 \\
Innovation costs too high & 0.261 & 0.439 & 0 & 1 \\
Excessive get-out clause & 0.031 & 0.176 & 0 & 1 \\
Lack of knowledge about financing & 0.044 & 0.207 & 0 & 1 \\
Collateral & 71.048 & 22.698 & 4.241 & 302.444 \\
Banking debt ratio & 17.678 & 15.758 & 0 & 92.307 \\
Own financing ratio & 31.827 & 24.195 & -609.459 & 90.136 \\
Gross operating profit margin & 18.248 & 19.416 & -197.600 & 76.850 \\
\hline \hline Sources : Centrale de Bilans (Banque de France), FIT (Sessi) and EAE (INSEE)
\end{tabular}




\section{Technical Appendix: DGP Methods}

Here we detail the methodology for generating data according to the Data Generating Processes discussed in the Monte Carlo Section above.

The main generating equations are:

$$
\begin{gathered}
\text { ystar } 1=x 1[\text { nobs }, k x 1] * \text { beta } 1+\text { gamma } * y 2+\text { eps } 1, \quad y 1=1(\text { ystar } 1>0) \\
\text { ystar } 2=x 2[\text { nobs }, k x 2] * \text { beta } 2+\text { delta } * y 1+\text { eps } 2, \quad y 2=1(\text { ystar } 2>0)
\end{gathered}
$$

\section{$14.1 \gamma$ unrestricted, $\delta=0$}

$$
\begin{gathered}
\text { ystar } 1=x 1[\text { nobs, } k x 1] * \text { beta } 1+\text { gamma } * y 2+\text { eps } 1, \quad y 1=1(\text { ystar } 1>0) \\
\text { ystar } 2=x 2[\text { nobs }, k x 2] * \text { beta } 2+\text { eps } 2, \quad y 2=1(\text { ystar } 2>0)
\end{gathered}
$$

Given the recursivity of the $\gamma \cdot \delta=0$ restriction in this case, ystar 2 is generated first, which gives $y 2$. This is then plugged into the RHS of the ystar 1 equation thus allowing ystar 1 and $y 1$ to be obtained.

$$
\begin{aligned}
14.2 \gamma & \geq 0, \delta \leq 0 \\
& 0 \leq \text { eps } 1+x 1 * b 1 \leq \text { gamma, }- \text { delta } \leq \text { eps } 2+x 2 * \text { beta } 2 \leq 0
\end{aligned}
$$

Accept-reject methods are used to generate the data so that these restrictions on the data are satisfied.

\section{3 $\gamma \leq 0, \delta \geq 0$}

$$
- \text { gamma } \leq \text { eps } 1+x 1 * b 1 \leq 0,0 \leq \text { eps } 2+x 2 * \text { beta } 2 \leq- \text { delta }
$$

Accept-reject methods are used to generate the data so that these restrictions on the data are satisfied.

\subsection{Algorithm for generating standard Normal variate trun- cated to lie outside $[\lambda,-\lambda]$}

We present here an algorithm for generating truncated normal variates to ensure the coherency of the non-recursive model under prior sign restrictions:

Let $z \sim N(0,1)$ and define $\tau \sim z \mid\{z \notin[\underline{\lambda}, \bar{\lambda}]\}$ Then $c d f(z): F(z)=\Phi(z)$ and

$$
c d f(\tau): F(\tau)= \begin{cases}\frac{\Phi(z)}{1-\Phi(\bar{\lambda})+\Phi(\underline{\lambda})} & \text { if } z<\underline{\lambda} \\ \frac{\Phi(\underline{\lambda})}{1-\Phi(\bar{\lambda})+\Phi(\underline{\lambda})} & \text { if } \underline{\lambda}<z \leq \bar{\lambda} \\ \frac{\Phi(z)-\Phi(\bar{\lambda})+\Phi(\underline{\lambda})}{1-\Phi(\bar{\lambda})+\Phi(\underline{\lambda})} & \text { if } z>\bar{\lambda}\end{cases}
$$


This algorithm is exact for a univariate $z$ truncated on $\{z \notin[\underline{\lambda}, \bar{\lambda}]\}$, but it will not work for higher dimensions. For DGPs with higher dimensions, accept-reject methods are preferable, though others exist (e.g., Gibbs resampling — see Hajivassiliou and McFadden (1998) for an explanation). 